\title{
A Study of Competitiveness between Low Cost Airlines andHigh-Speed-Rail: A Case Study of Southern Corridor in Thailand
}

\author{
Piti Chantruthai $^{1, a}$, Sirirat Taneerananon ${ }^{2, b}$, and Pichai Taneerananon ${ }^{3, c}$ \\ 1 Faculty of Industrial Technology, Nakhon Si Thammarat Rajabhat University, Nakhon Si Thammarat \\ 80280, Thailand \\ 2 Faculty of Liberal Arts, Prince of Songkla University, Songkhla 90110, Thailand \\ 3 Department of Civil Engineering, Faculty of Engineering, Prince of Songkla University, Songkhla 90110, \\ Thailand \\ E-mail: apchantruthai@gmail.com(Corresponding author),btsirirat@hotmail.com, cbreathislife@yahoo.com
}

\begin{abstract}
This paper investigates the competitiveness between Low Cost Airlines (LCA) and High Speed Rail (HSR) on the southern corridor where LCA predominate at present. A study of passengers' Origin and Destination (O-D) pairs in southern corridor of Thailand was conducted. The O-D surveys were carried out for the 2 sections of the southern corridor: Surat Thani-Bangkok (ST-BKK) and Hat-Yai -Bangkok (HY-BKK). The competitiveness between HSR and LCA and the Willing-To-Pay for the HSR fare were analysed using factors determined by the multinomial logistic regression model and binary logistic regression model, respectively. Competitiveness between HSR and LCA did not depend only on travel time alone but also on factors such as fare difference, users'occupation, household income, education level and trip purposes. The result of the Willingness-To-Pay for the HSR fare showed the fare for O-D pairs between ST-BKK and HY-BKK at 1.8 THB $/ \mathrm{km}(\mathrm{US} \$ 0.06 / \mathrm{km})$ and $1.5 \mathrm{THB} / \mathrm{km}$ (US\$ $0.05 / \mathrm{km}$ ), respectively. The average HSR fare was $1.65 \mathrm{THB} / \mathrm{km}$ (US\$ $0.055 / \mathrm{km}$ ). This is in comparison to the fare of HY-BKK $2.45 \mathrm{THB} / \mathrm{km}$ (US\$ $0.08 / \mathrm{km}$ ) for a LCA, and an average of $2.65 \mathrm{THB} / \mathrm{km}$ (US\$ $0.09 / \mathrm{km}$ ) for another LCA. It is seen that the fare differential of $1 \mathrm{THB} / \mathrm{km}$ (US\$ $0.03 / \mathrm{km}$ ) could be significant in making passengers change from LCA to HSR.
\end{abstract}

Keywords: Low cost airlines, high speed rail, willingness-to-pay.

ENGINEERING JOURNAL Volume 18 Issue 2

Received 3 July 2013

Accepted 15 October 2013

Published 18 April 2014

Online at http://www.engj.org/

DOI:10.4186/ej.2014.18.2.141 


\section{Introduction}

Bus, Train and Air modes are the prevalent options for intercity transport in Thailand. Of these modes, buses take up the highest proportion of passengers, or $87 \%$, while trains and airlines cater to much smaller proportions, i.e. $10 \%$ and $3 \%$, respectively. Most trips on domestic commercial airlines are for long distances. Don Muang airport in Bangkok serve as hubs for flights to and from destinations in all geographic regions. Airline ridership has remained low when compared with those of other travel modes due to the much higher fare structure does much to discourage ridership leaving only a very small percentage of travelers with the means to afford this travel mode. In addition, access to flying is inconvenient given that most airports are situated far out from the city, and passengers are required to go through the time-consuming process of boarding check-in. However, during the 10-year period from 1999 to 2009 , domestic passenger volume showed a steadily increasing trend, from 14.37 million in 1999 to 24.54 million in 2009. This increase was in line with the growth of low-cost airline business from its inception in 1999 [1].

The strategic plan of High Speed Rail (HSR) 1 was studied by the Office of Transport and Traffic Policy and Planning (OTP) in 2010, which proposed four HSR corridors and investment plans over an 18year project duration from 2015 to 2032. The HSR corridors cover all the regions of Thailand and starting from Bangkok to Chiang Mai $(745 \mathrm{~km})$ in the north, to Nong Kai $(615 \mathrm{~km})$ and Ubon Ratchathani $(570 \mathrm{~km})$ in the northeast, Aranyaprathet $(250 \mathrm{~km})$ and Chanta Buri $(330 \mathrm{~km})$ in the east and Pradang Besar $(982 \mathrm{~km})$ in the south [2] (see Fig. 1). The former government of Prime Minister Abhisit Vejjajiva had approved in principle a framework for negotiations with China on the HSR Kunming - Singapore project from Nong Kai to Bangkok and Rayong in the east, and from Bangkok to Padang Besar, which was estimated at almost THB 560 billion (US\$ 19 billion)2. However, after the general election in 2011, the new Prime Minister, Yingluck Shinawatra decided to delay the HSR project on routes connecting Bangkok, Nong Kai, Rayong and Padang Besar because of the impact from the problem of HSR route in Laos. On April 2012, under the joint collaboration, the Chinese government undertook a feasibility study of the two lines from Bangkok to Chiang Mai and Bangkok to Nong Kai. The result of the study suggested that for Bangkok - Chiang Mai line, train running with the maximum speed of $300 \mathrm{~km} / \mathrm{h}$ should be selected and the maximum speed of $250 \mathrm{~km} / \mathrm{h}$ would be appropriate for Bangkok to Nong Kai line[3].

On 19th March 2013, the cabinet approved a special plan to borrow THB 2 trillion (US\$ 68 billion) for investment in the logistics and transport infrastructure projects over the seven-year (2014-2020) period. The total of THB 2 trillion for infrastructure investment includes: THB 1.65 trillion for double track railway and the four high speed rail projects, THB 307 billion for water transport projects, THB 243 billion for road transport projects and the highway checkpoint THB 12.2 billion. The government plans to start construction bidding in 2014; the first phase of high speed rail will cover four routes - Bangkok Pitsanulok, Bangkok - Nakhon Ratchasima, Bangkok - Pattaya and Bangkok - Hua Hin and will be completed in 2018. The continuation of the routes are to be completed in the second-phase construction by 2022. The cost estimates for high speed rail vary according to the geographical areas from about 300 million baht $/ \mathrm{km}$ (US\$ 10 million $/ \mathrm{km}$ ) to 600 million baht $/ \mathrm{km}$ (US\$ 20 million $/ \mathrm{km}$ ) [4].

The government expressed confidence that the high speed rail system would increase options for the people on transportation connectivity, reduce transportation cost, spread prosperity to the rural areas and reduce income disparity. However, studies have shown that the competitive advantage of HSR over air is in the medium distance while for the short distance road transportation would be more efficient[2]. Factors affecting the competitiveness of HSR with other modes are not only the difference of travel time, and frequency but also the differences in fare and convenience. The objectives of this paper are to review HSR from a worldwide perspective, to study factors determining the competitiveness between low cost airlines and HSR of O-D pairs in southern corridor and the Willingness-To-Pay for HSR fare.

\footnotetext{
${ }^{1}$ According to the International Union of Railways (UIC), the general definitions of high speed rail is the train that runs on decicated tracks and is designed for speed over $250 \mathrm{~km} / \mathrm{h}$, or on upgraded tracks for speed over $200 \mathrm{~km} / \mathrm{h}$. ${ }^{2}$ Exchange rate (on Febuary 15 $5^{\text {th }}, 2013$ ): 1 US $\$=30 \mathrm{THB}$
} 


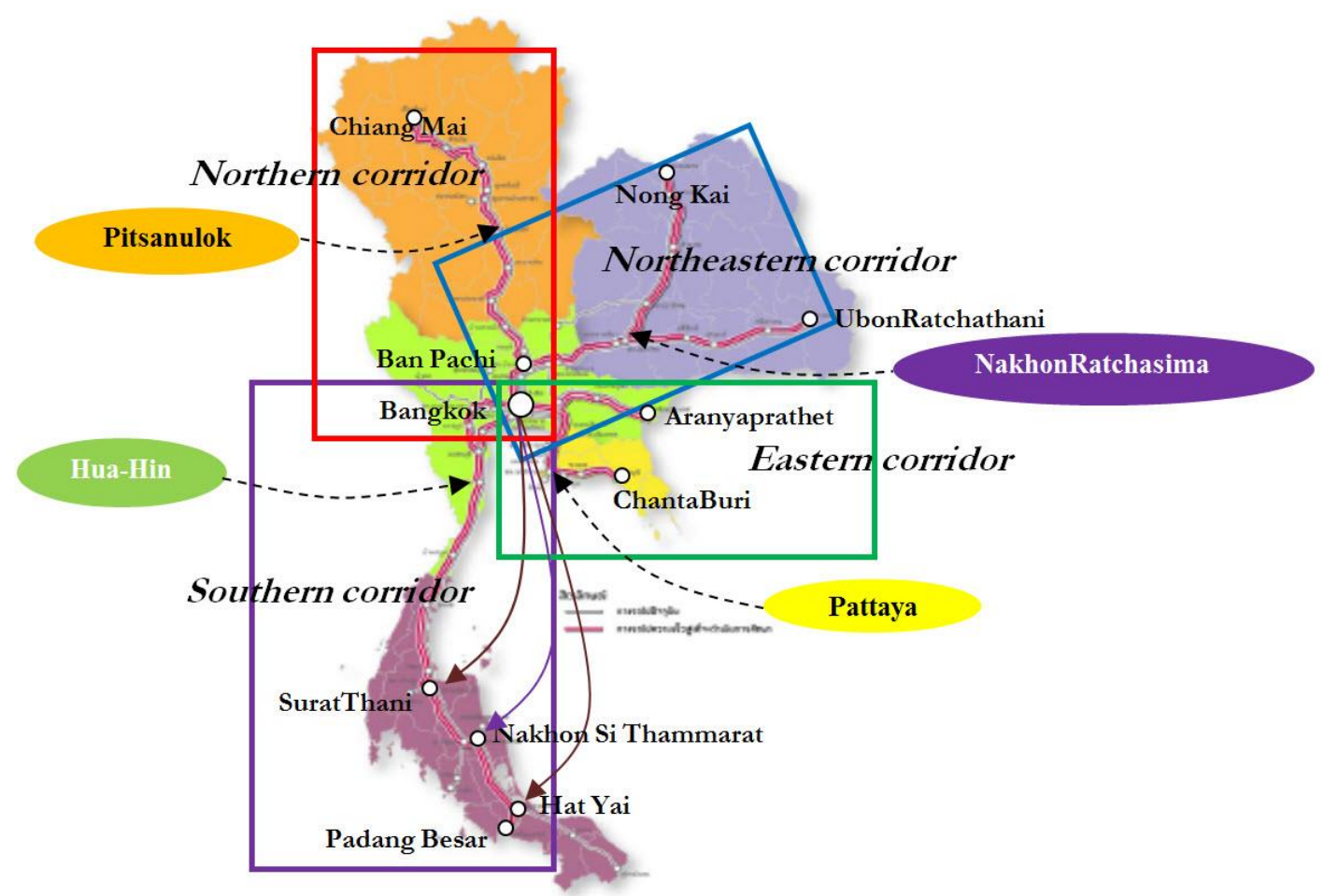

Fig. 1. High Speed Rail lines on four corridors and the first phase O-D plan. (Source: Adapted from OTP, 2010.)

\section{High Speed Railfrom Worldwide Perspective}

\subsection{High-Speed-Rail Network in the World}

In 2012, the total length of HSR networks in the world are about $20,722 \mathrm{~km}$, Europe has a share $34.5 \%$ of the world HSR network in operation, Asia $63.8 \%$ and other countries $1.7 \%$. There are $14,610 \mathrm{~km}$ of HSR lines under construction and 16,348 $\mathrm{km}$ of HSR lines are planned (see Fig. 2). The total length of HSR lines in the world are expected to grow to $51,681 \mathrm{~km}$ in 2025, of which 18,264 km will be in Europe, 31,087 km in Asia, and 2,330 km in other countries(see Table 1) [5]. Although Japan has over 48 years of experience with the HSR technology when it was started in 1964, but until recently and in terms of route length, China has emerged as a new player with the longest HSR network in the world. By 2012, China has plans to expand its HSR to $13,000 \mathrm{~km}$ of route length comprising $8,000 \mathrm{~km}$ for a maximum speed of $350 \mathrm{~km} / \mathrm{h}$ and $5,000 \mathrm{~km}$ for a maximum of speed $250 \mathrm{~km} / \mathrm{h}$. However, after the HSR crash in Wenzhou in July 2011, the total length of HSR lines has only reached 9,356 km in operation by December 2012 [6].

According to the construction plan, the total length of HSR lines in China will be almost 2.5 times of the current status by 2025 or about $44 \%$ of the world HSR network in operation. In 2008, the first route of HSR was opened between Beijing - Tianjin for the Olympic games with a maximum speed of $250 \mathrm{~km} / \mathrm{h}$. China achieved the initial agreement for construction the CHINA - ASEAN HSR lines with Vietnam, Laos, Cambodia, Thailand, Malaysia and Singapore[7]. Kunming is the starting point of the Kunming - Singapore Economic Corridor which ends in Singapore, a total length of $3,900 \mathrm{~km}$. This line is to open for service in 2020 [8](see Fig. 3).

As regards the latest development, a new High-Speed Rail line in Asia was opened on June 30, 2011, connecting two mega cities of China, Beijing and Shanghai. This line is the longest HSR line in the world covering a distance of $1,318 \mathrm{~km}$ and was construced in one phase with an investment of US $\$ 43.7$ billion [9]. The HSR which runs on standard track has two running speeds $300 \mathrm{~km} / \mathrm{h}$ and $250 \mathrm{~km} / \mathrm{h}$. It can cut travel time from $10 \mathrm{hrs}$ by bus to $5 \mathrm{hrs}$ at $300 \mathrm{~km} / \mathrm{h}$, and $8 \mathrm{hrs}$ at $250 \mathrm{~km} / \mathrm{h}$. Although the travel time at 300 $\mathrm{km} / \mathrm{h}$ is more than two hours longer than flight time, but the HSR fare is cheaper than the comparable airfare. The airline saw a big drop in their market share on this route after HSR was opened, this forced it to cut ticket prices as much as $65 \%$ in order to retain its market share and be competitive with HSR [10]. 
The length of HSR in Europe will reach 18,264 km by 2025 or almost 2.6 times the 2012 total length (see Fig. 4). As of 2012, Spain has the longest HSR lines in the EU of nearly 2,276 km, followed by France $2,036 \mathrm{~km}$ and Germany 1,334 km. However, by 2025, France's HSR network is expected to grow to 5,200 $\mathrm{km}$, close to that of Spain which will reach 5,525 km.

As of 2009, the US has HSR projects with maximum speed $300 \mathrm{~km} / \mathrm{h}$ and covers 3 sections: FresnoBakersfield $483 \mathrm{~km}$, Sacramento-Fresno $147 \mathrm{~km}$ and Bakersfield-Los Angeles $147 \mathrm{~km}$. The purposes of these projects are to reduce oil consumption, cut travel time and improve the environment [11]. Total length of the US HSR lines will be expanded to $1,139 \mathrm{~km}$ in 2025 or $2.2 \%$ of the world HSR lines.

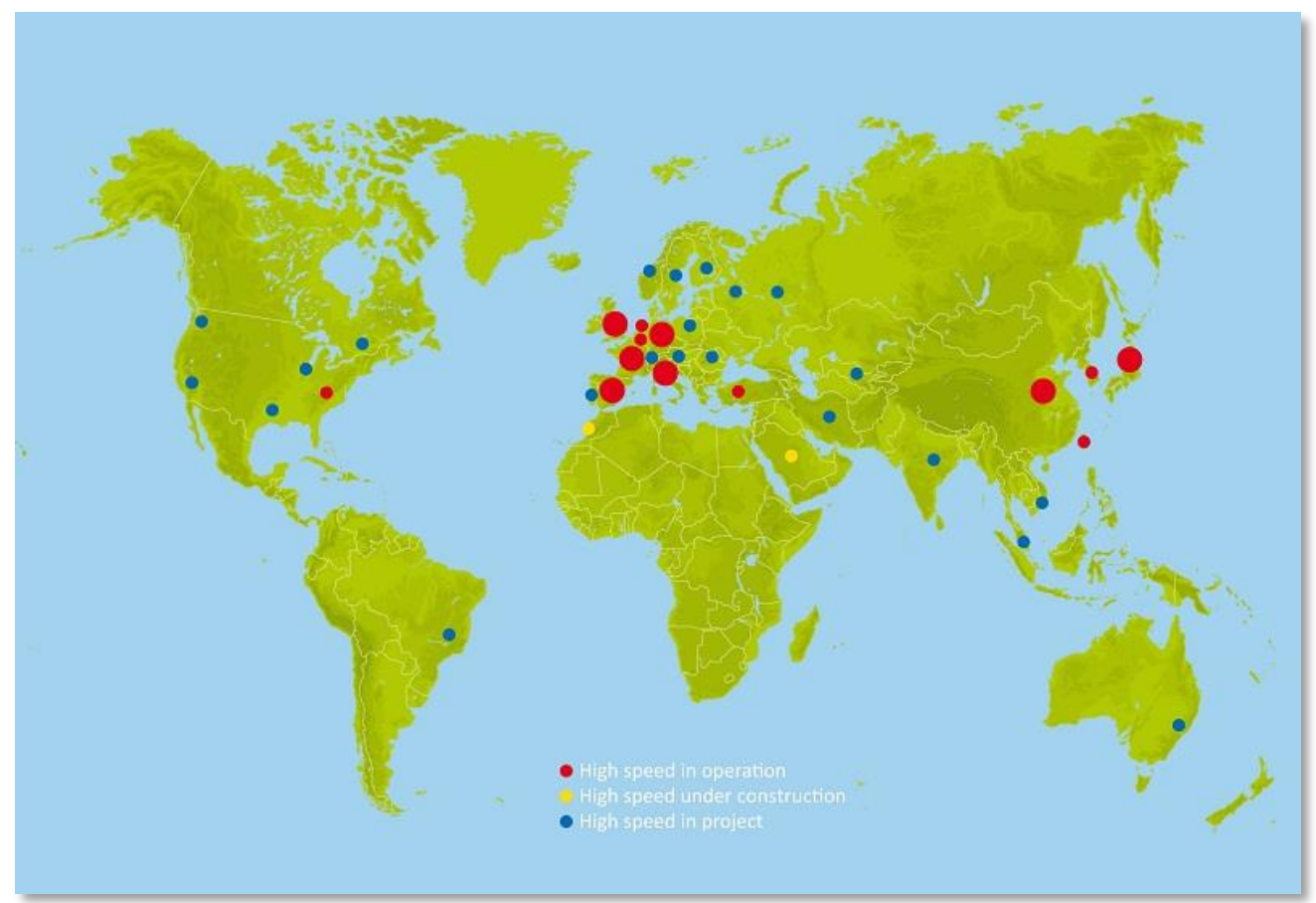

Fig. 2. The world High-Speed-Rail network in 2012 [12].

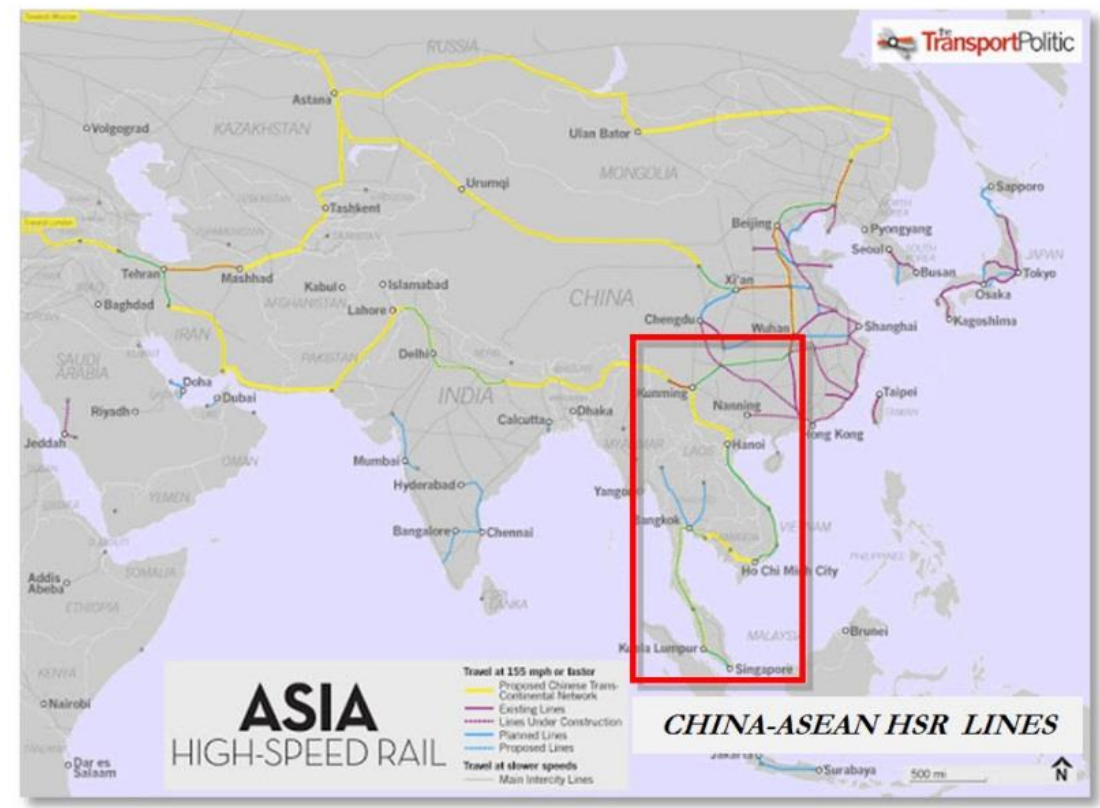

Fig. 3. Asia High-Speed-Rail and China-ASEAN High-Speed-Rail lines projects [13]. 
Table 1. State of the World's HSR network in 2012 and 2025.

\begin{tabular}{|c|c|c|c|c|}
\hline \multirow[b]{2}{*}{ Area } & \multicolumn{4}{|c|}{ The total length of HSR lines in each region $(\mathrm{km})$} \\
\hline & In operation & $\begin{array}{c}\text { Under } \\
\text { construction }\end{array}$ & Planned & $\begin{array}{l}\text { Total network } \\
\quad \text { in } 2025\end{array}$ \\
\hline Asia & 13,221 & 11,606 & 6,259 & 31,087 \\
\hline - China & 9,356 & 9,485 & 3,777 & 22,619 \\
\hline - Taiwan & 345 & - & - & 345 \\
\hline - India & - & - & 495 & 495 \\
\hline - Japan & 2,664 & 782 & 180 & 3,626 \\
\hline - Saudi Arabia & - & 550 & - & 550 \\
\hline - South Korea & 412 & 186 & 49 & 647 \\
\hline • Turkey & 444 & 603 & 1,758 & 2,805 \\
\hline Europe & 7,139 & 2,804 & 8,321 & 18,264 \\
\hline - Austria & 93 & - & - & 93 \\
\hline - Belgium & 209 & - & - & 209 \\
\hline - France & 2,036 & 757 & 2,407 & 5,200 \\
\hline - Germany & 1,334 & 428 & 495 & 2,257 \\
\hline - Italy & 923 & - & 395 & 1,318 \\
\hline - Netherlands & 120 & - & - & 120 \\
\hline - Poland & - & - & 712 & 712 \\
\hline - Portugal & - & - & 1,006 & 1,006 \\
\hline • Russia & - & - & 650 & 650 \\
\hline - Spain & 2,276 & 1,547 & 1,702 & 5,525 \\
\hline - Sweden & - & - & 750 & 750 \\
\hline - Switzerland & 35 & 72 & - & 107 \\
\hline • UK & 113 & - & 204 & 317 \\
\hline Other countries & 362 & 200 & 1,768 & 2,330 \\
\hline - Morocco & - & 200 & 480 & 680 \\
\hline - Brazil & - & - & 511 & 511 \\
\hline - USA & 362 & - & 777 & 1,139 \\
\hline World total & 20,722 & 14,610 & 16,348 & 51,681 \\
\hline
\end{tabular}

Source: UIC, 2013. High Speed Lines in the World (Updated 1 ${ }^{\text {st }}$ April 2013).

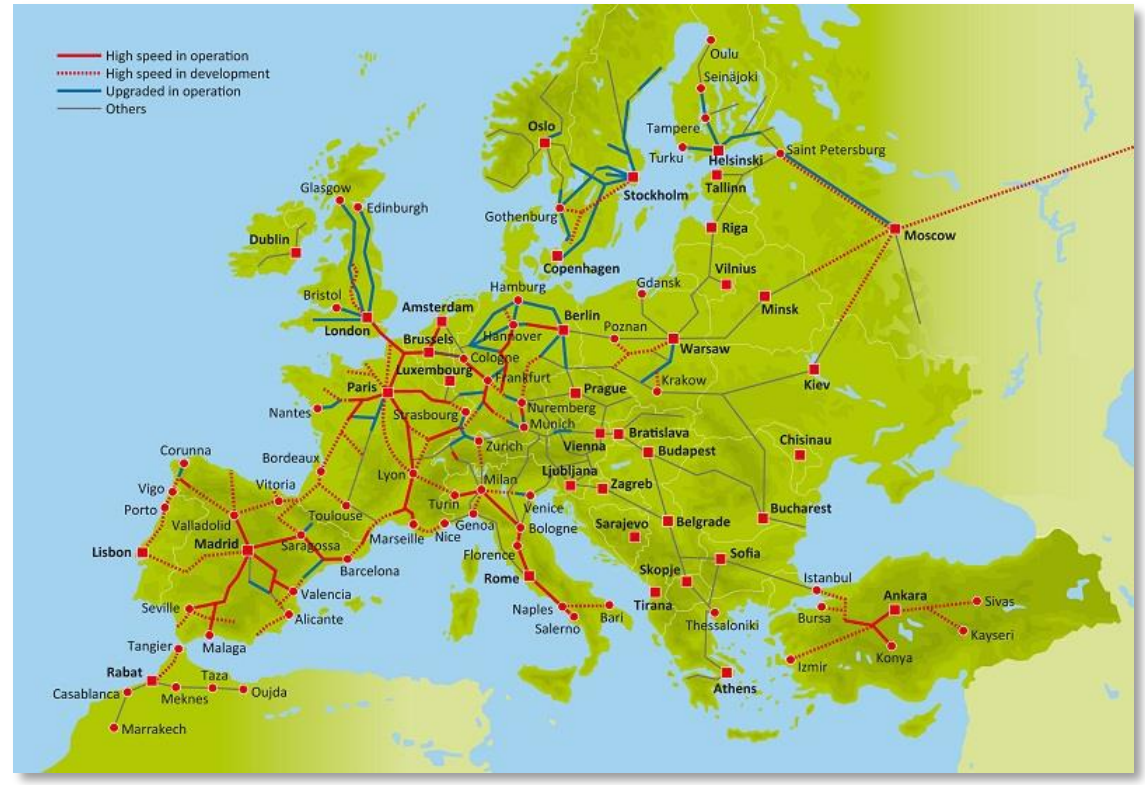

Fig. 4. High-Speed-Rail network in Europe [14]. 


\subsection{Benefits of High-Speed-Rail}

After the start of operation of first HSR in 1964 in Japan and followed by many countries in Europe and other countries in Asia, HSR has become a popular mode for travel. The number of HSR passengers in Japan has increased from 60,539/day in 1964 to 762,671/day in 2004 due to many benefits i.e. reduction in fuel consumption, traffic accident, pollution from transportation; and promotion of regional development and urbanization[15]. Figure 5 shows the example of the trend in the number of HSR passenger-km in Japan (1964-2010)[16] and some countries in Europe (1990-2006)[17]. In Japan the number of passenger$\mathrm{km}$ has increased more than $88 \%$ over the 47 - year span, for Europe, the figure is more than $83 \%$ over 17 year period (see Fig. 5).

HSR is known to command the largest market share for travel distance around $300-750 \mathrm{~km}$, however, for distance below $300 \mathrm{~km}$, the main market share goes to private car and for the longer distance over 750 $\mathrm{km}$, market share of airlines dominates over other modes (see Fig. 6) [18]. HSR competes with airlines between medium to long distance where HSR fare is set below air fare but higher than the fare of intercity bus and conventional rail. Table 2 shows a comparison between HSR and air fare, Tokyo-Osaka corridor in Japan shows the highest HSR fare of all selected corridor at US\$ 0.26 per $\mathrm{km}$ while the Beijing-Shanghai corridor in China shows the lowest HSR fare at US $\$ 0.06 \mathrm{per} \mathrm{km}$. The airfare for Paris-Lyon is the highest at US $\$ 1.04$ per $\mathrm{km}$, while the lowest fare is on the Paris-London route at US\$ 0.24 per $\mathrm{km} \mathrm{[19].} \mathrm{Experience}$ from Europe and Japan indicates that HSR takes a substantial market share from airlines (see Fig. 7) [20].
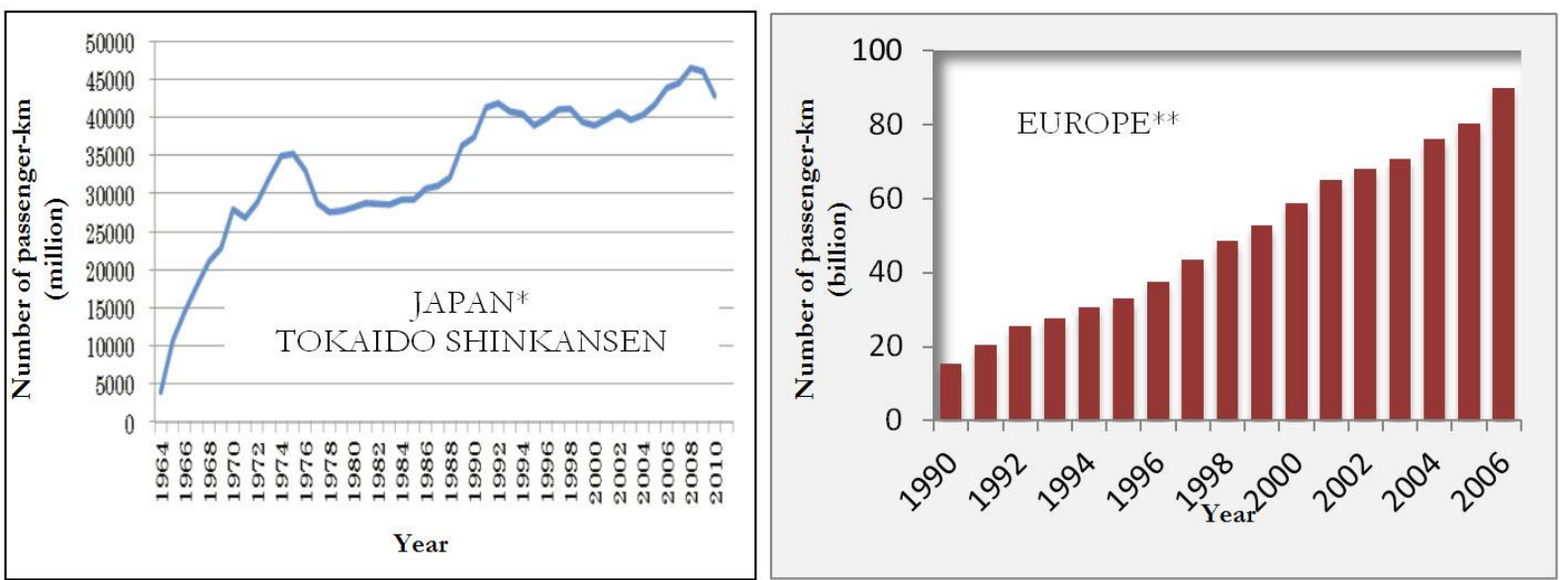

Fig. 5. The statistics of number of passenger-km: Japan-TokaidoShinkansen (1964-2010) and Europe (1990-2006).

Source: *Sakamoto, R. 2012; **European Commission. 2012.

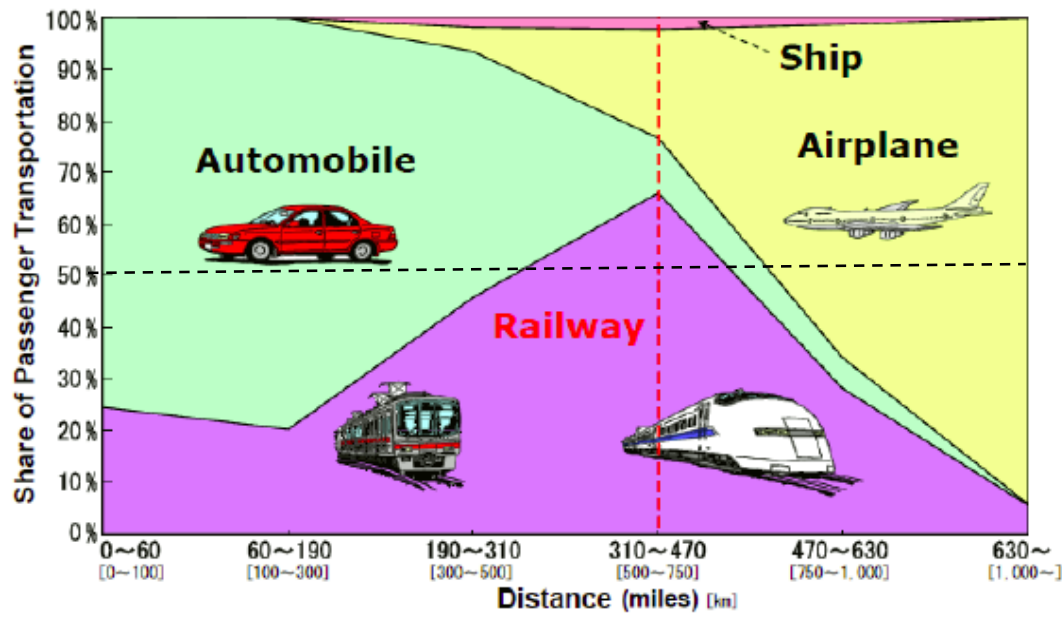

Fig. 6. Modal share of passenger transport in Japan.

Source: Chang Min Y, et al., 2011. 
Table 2. Comparison of fare between HSR and airlines in the same routes of each corridor.

\begin{tabular}{|c|c|c|c|c|c|c|c|}
\hline \multirow{2}{*}{ Corridor (Type of HSR) } & \multirow{2}{*}{$\begin{array}{c}\text { Length } \\
(\mathrm{km})\end{array}$} & \multirow{2}{*}{$\begin{array}{c}\text { HSR- } \\
\text { traveltime } \\
(\mathrm{hrs})\end{array}$} & \multicolumn{2}{|c|}{ HSR fare } & \multicolumn{2}{|c|}{ Air fare } & \multirow{2}{*}{$\begin{array}{c}\text { Air } \\
\text { fare } / \text { HSR } \\
\text { fare }\end{array}$} \\
\hline & & & (US\$) & (US\$ $/ \mathrm{km})$ & (US\$) & $(\mathrm{US} \$ / \mathrm{km})$ & \\
\hline Tokyo-Osaka (Nozomi) & 553 & 2.65 & 141 & 0.26 & 246 & 0.45 & 1.73 \\
\hline Koln-Frankfurt (ICE) & 177 & 1.17 & 42 & 0.24 & 151 & 0.85 & 3.54 \\
\hline Paris-London (Eurostar) & 492 & 2.25 & 63 & 0.13 & 116 & 0.24 & 1.85 \\
\hline Madrid-Barcelona (AVE) & 621 & 2.63 & 74 & 0.12 & 165 & 0.27 & 2.25 \\
\hline Paris-Lyon (TGV) & 396 & 2.15 & 32 & 0.08 & 411 & 1.04 & 13.00 \\
\hline Beijing-Shanghai $(300 \mathrm{~km} / \mathrm{h})$ & 1,318 & 7.93 & $88^{*}$ & 0.07 & 411 & 0.31 & 4.43 \\
\hline Beijing-Shanghai $(250 \mathrm{~km} / \mathrm{h})$ & 1,318 & 4.80 & $65^{*}$ & 0.06 & 411 & 0.31 & 5.17 \\
\hline
\end{tabular}

Remark: *HSR fare for 2 nd class.

Souce: Freemark, Y., 2009.

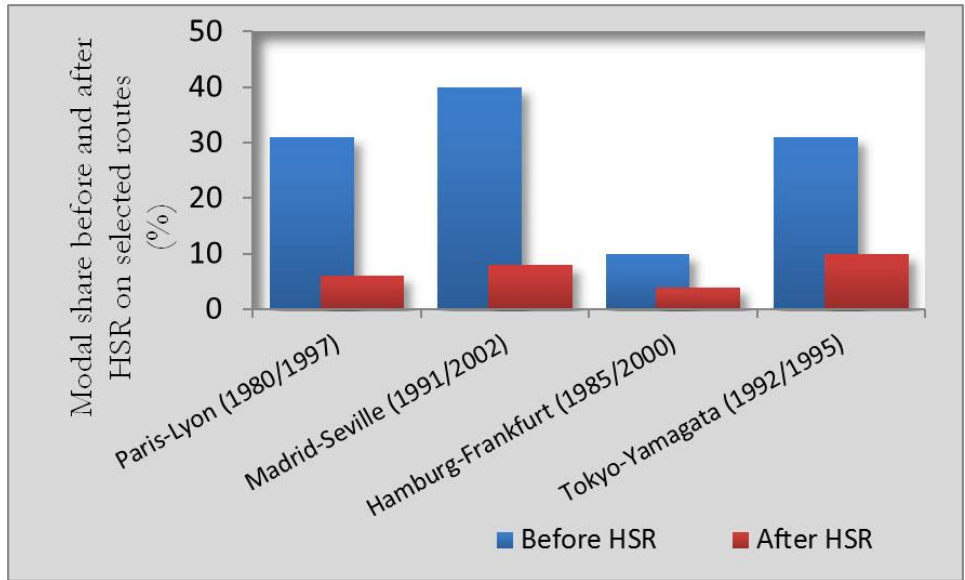

Fig. 7. Modal share of airlines before and after HSR operated.

Source: Barron, I., et al., 2009

\section{Intercity Transport Situation in Thailand}

\subsection{Intercity Passenger Travel Demand}

During 2005-2009, travel volumes on public transport showed an average of 460 million passenger-trips /year. The proportion of passengers choosing to travel by intercity buses was a predominant $87 \%$, followed by the rail and air modes, at $10 \%$ and 3\% respectively. Intercity bus and airline ridership showed an average increase of $7.9 \%$ and $5.8 \%$ per year respectively, while the rail ridership showed an average drop of $2.1 \%$ per year (see Table 3) [21].

Table 3. Intercity passenger travel demand for public transport during 2005-2009.

\begin{tabular}{cccccccc}
\hline \multirow{2}{*}{ Modes } & \multicolumn{5}{c}{ Years (million passenger-trips) } & \multirow{2}{*}{ Average } & \multirow{2}{*}{ \% Avg. diff. / year } \\
\cline { 2 - 5 } & $\mathbf{2 0 0 5}$ & $\mathbf{2 0 0 6}$ & $\mathbf{2 0 0 7}$ & $\mathbf{2 0 0 8}$ & $\mathbf{2 0 0 9}$ & & -2.1 \\
Rail & $49(13.7)$ & $48(12.2)$ & $45(8.2)$ & $48(9.4)$ & $45(9.2)$ & $47(10.5)$ & 5.8 \\
Air & $11(3.0)$ & $12(3.0)$ & $14(2.5)$ & $14(2.7)$ & $14(2.9)$ & $13(2.9)$ & 7.9 \\
Intercity Bus & $299(83.3)$ & $334(84.8)$ & $493(89.3)$ & $451(87.9)$ & $427(87.9)$ & $401(86.6)$ & -2.1 \\
Total & $359(100)$ & $394(100)$ & $552(100)$ & $513(100)$ & $486(100)$ & $461(100)$ & \\
\hline
\end{tabular}

Remark: (\%).

Source: OTP, 2009.

The result of OTP's study showed that intercity passenger travel volume for 2009 grew to 1.20 billion passenger-trips/year with private-car and public-transport modes taking up 59\% and 41\% of the volume respectively. The public transport mode comprise intercity bus, train and commercial airline, catered to the demand at 36\%, 4\% and 1\%, respectively. Because practically all sections of Thailand's national highways 
are built to high international standards, the demand for highway use has been increasing at the rate of 3.6\% per year [22].

\subsection{Modal Competition}

The intercity travel modes under the current investigation include: Private Car, Bus, Train and Airline. Origin-Destination Surveys (O-D) were conducted in order to analyze the relationship between distance and travel time in each mode by linear regression method. The destinations were selected for trips originating from Bangkok to all twenty one provinces for airline, train and bus and three hundred questionnaires were used for interviewing car respondents in the southern corridor (see Fig. 8).

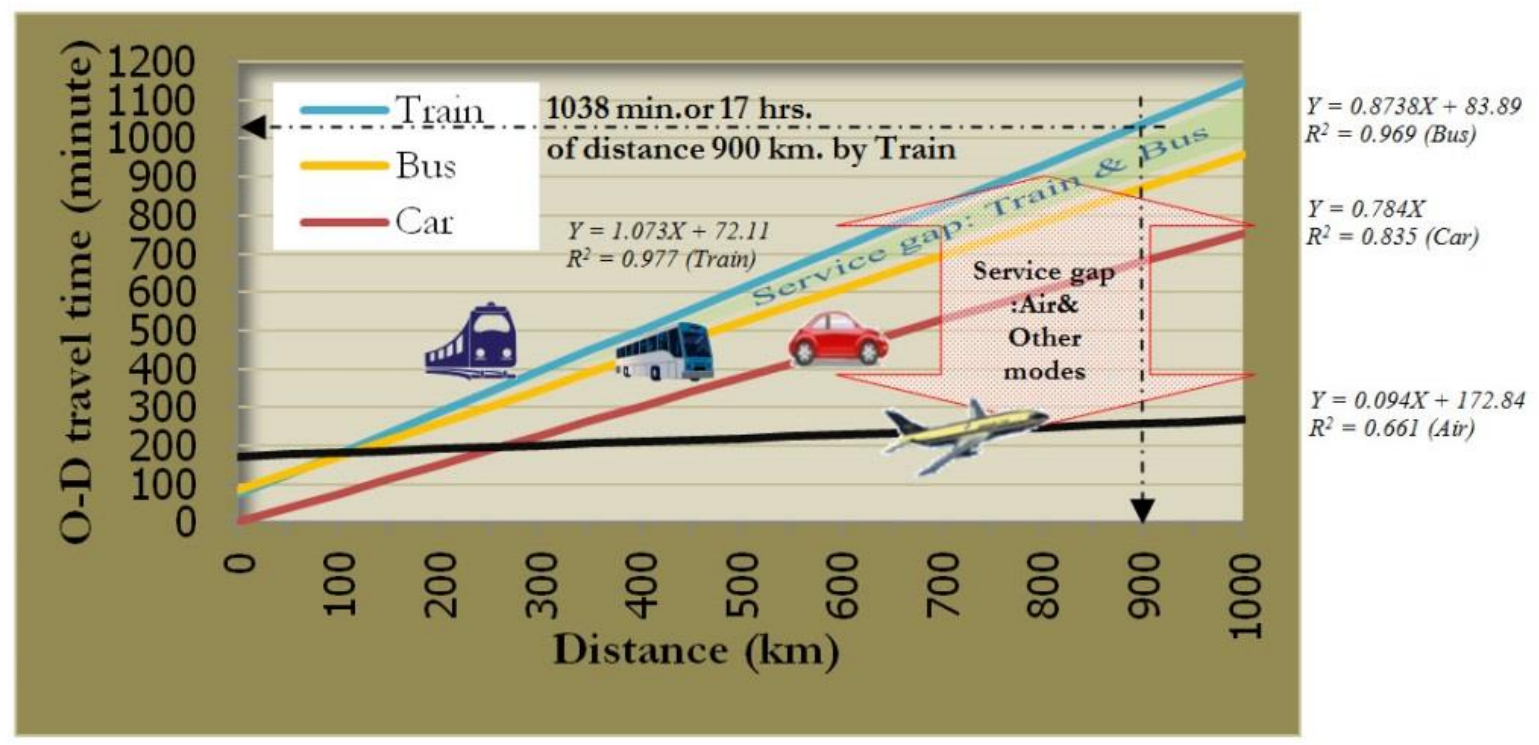

Fig. 8. Relationship between O-D travel time and distance in each mode.

Source: Calculated by authors.

Remark: $X_{i}=$ Travel distance of mode $i(\mathrm{~km}) ; Y_{i}=$ Travl time of mode $i(\min )$.

Figure 8 shows that train travel is not as popular as it should be despite its lower fare scale due to the much longer travelling time when compared with other modes on the same distance travelled. Air travel is often out of reach due to its relatively high prices. All of this makes the intercity bus the most popular travel option (see Table 3). Intercity bus, train and private carhave advangtage over air mode for short distance journeys, in the range of $100-250 \mathrm{~km}$. However, for the jouney distance over $250 \mathrm{~km}$, air is faster than other modes. The relationship between O-D pairs travel time and distance which refect the relative speed of each mode shows two service gaps as indicated in the figure: the first gap lies between the train and the bus modes, and the second one between the air and other travel modes. The first gap widens with travel distance, an indication that travel time on the train mode expands disproportionately with the time required for the bus mode on the same distance travelled. This reflects the inefficiency of train services which need upgrading. The gap between the air and other modes indicates the need for innovative options in order to fill it; for example, HSR with service speeds of $250 \mathrm{~km} / \mathrm{h}$ or higher.

However, the State Railway of Thailand (SRT) has the development plans for double track rail project which is planned for nationwide service coverage with a combined route length of $3,039 \mathrm{~km}$, and to be implemented over 15 years. Development is staged in three phases as described below.

- Phase I: From 2010 to 2014, a period of 5 years; total route length $767 \mathrm{~km}$; project investment THB 75 billion (US $\$ 2.5$ billion).

- Phase II: From 2015 to 2019, total route length 1,025 km; project investment THB 75 billion (US $\$ 2.5$ billion).

- Phase III: From 2020 to 2024, total route length 1,247 km; project investment THB 99 billion (US\$3.3 billion). 
Rail infrastructure upgrades are necessary to accommodate the planned Express Train and HSR. Either new or upgraded rail systems as well as E\&M will be required to support train operations at higher speeds. It is possible to upgrade a portion of existing rolling stock for use on the new Express track. Existing track (1.00 m gauge) can also be improved to support speeds up to $120 \mathrm{~km} / \mathrm{h}$. At the same time, the existing signaling system may be upgraded for compatibility with the express system. For the high-speed train operating at $250 \mathrm{~km} / \mathrm{h}$ on single track, all-new rolling stock will have to be procured. The track required for HSR will be the standard gauge $(1.435 \mathrm{~m})$ dedicated track which cannot be linked with SRT's narrow-gauge lines, with the Airport Rail Link being an exception. Elevated rail will be necessary where a line crosses a traffic intersection [23].

The medium-haul option for journeys of about $150-550 \mathrm{~km}$, is expected to fill the service gap between existing road-rail modes. From the O-D surveys, the average service speed of existing train is found to be as low as $50 \mathrm{~km} / \mathrm{h}$. For a long distance such as $900 \mathrm{~km}$, an outdated SRT train requires 17 hours to cover it (see Fig. 8). In contrast, an express train (double track) running at $120 \mathrm{~km} / \mathrm{h}$ will be able to cover the distance in 8 hours and 30 minutes, thereby cutting current travel time by 8 hours and 30 minutes. Even greater travel time reductions will be possible where an HSR is employed. Competitiveness of HSR advantage other modes for medium distance journeys in the range of $150-550 \mathrm{~km}$ as shown in Fig. 9.

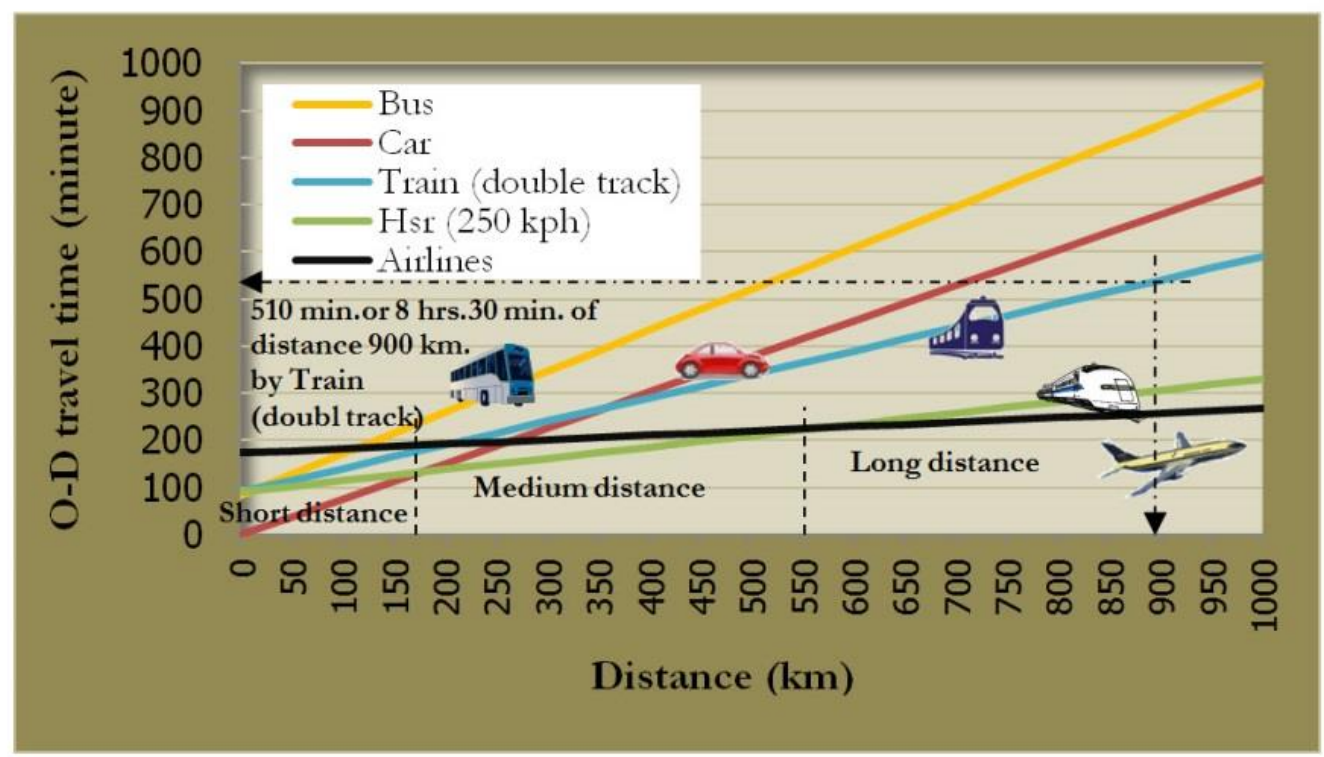

Fig. 9. Express train (double track) and HSR to fill in service gap between modes.

Source: Calculated by author.

\subsection{O-D Surveys Case Studyin Southern Corridor}

Surat Thani (ST) and Hat-Yai city (HY) were selected for trips originating of O-D case study to destination in Bangkok because of their locations being situated on HSR route plan of southern corridor. Distance between Bangkok to SuratThani is $644 \mathrm{~km}$ and distance between Bangkok to Hat-Yai city is $933 \mathrm{~km}$ as shown in Fig. 1. O-D surveys were conducted in order to analyze the behaviors of intercity passengers, modes under investigation include: private car, bus, train and airline. Travel behaviors are grouped according travel modes in each province. The study used primary data which were collected with the use of structured questionnaires. A methodology of research defines the processes of research, the method of analyzing the data for competitiveness between Train (double track) vs. LCA and HSR VS. LCA and the method of analyzing data for WTP for HSR fare. The processes of the research are summarized in Fig. 10 


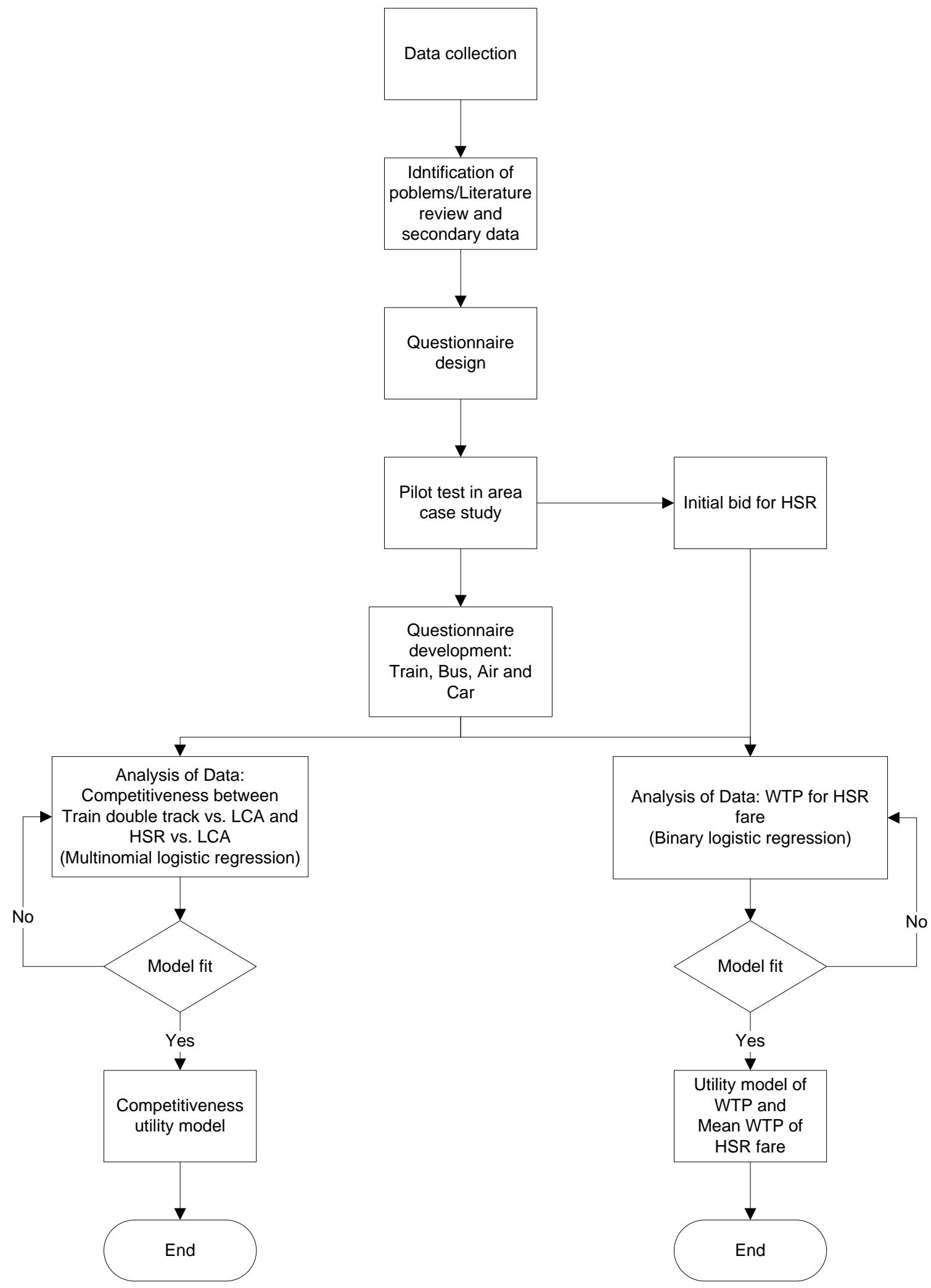

Fig. 10. Processes of the research.

Table 4 shows the characteristic of respondents and covers the data of socioeconomic and trip purpose of each mode for a sample of 1,268 respondents of SuratThani and a sample of 1,385 respondents of HatYai. The result can be summarized as follows: 
- Number of passengers travelled by public modes, most of the passengers chose to travel by train followed by bus and air between ST-BKK while airlines was the mode chosen by most passengers travelled between HY-BKK.

- Number of travellers by private car were estimated by using an occupancy rate at 1.3 persons/car. [24]

- Female travellers formed a higher percentage than male travellers in all travel modes between STBKK, whilst they made up a high percentage in train and air mode between HY-BKK.

- For marital status, the 'married status' made up the highest percentage The respondents' average ages in ST are higher than those in HY when compared between mode. Average ages are about 34-40 years old in ST and about $32-34$ years old in HY.

- In ST, the percentage of students travelled by train $(41.7 \%)$ and car $(34.6 \%)$ were the highest compared to other occupations whilst most of government officials selected to travel by bus $(39.5 \%)$ and air mode $(38.1 \%)$. For HY, the highest percentage of occupation was the students who chose to travel by train $(28.9 \%)$ and airline $(31.6 \%)$. Most of government officials chose to travel by bus $(33.7 \%)$ and $\operatorname{car}(30.7 \%)$.

- Most of the respondents' education level was bachelor degree $(>50 \%)$ except train passengers in HY where the percentage of below bachelor level was the highest (57.3\%).

- Similarly, the average of personal income and household income of respondents in both ST and HY show train passengers have the lowest income and air passengers the highest income.

- The main travel purpose of respondents by mode were to do business and go home by train, to do business and touring by bus and airline and go to work and business by car in ST. In HY the main travel purposes by mode were to do business and study by train, to do business and go home by bus, air and car.

Table 4. Characteristics of respondents: socioeconomic and trip purpose.

\begin{tabular}{|c|c|c|c|c|c|c|c|c|}
\hline \multirow{3}{*}{ Characteristics } & \multicolumn{8}{|c|}{ Percentage characteristics of respondents in each O-D pairs by modes } \\
\hline & \multicolumn{4}{|c|}{ SuratThani-BKK } & \multicolumn{4}{|c|}{ Hat-Yai-BKK } \\
\hline & Train & Bus & Air & Car & Train & Bus & Air & Car \\
\hline $\begin{array}{l}\text { Number of pax/day } \\
\text { (one-way trip) in } 2010\end{array}$ & 1,154 & 1,087 & 513 & 1,664 & 1,070 & 998 & 1,740 & 1,538 \\
\hline Number of respondents & 300 & 309 & 344 & 315 & 349 & 350 & 351 & 335 \\
\hline \multicolumn{9}{|l|}{ Gender } \\
\hline Male & 42.3 & 46.3 & 47.7 & 41.3 & 40.1 & 59.1 & 49.6 & 75.8 \\
\hline Female & 57.7 & 53.7 & 52.3 & 58.7 & 59.9 & 40.9 & 50.4 & 24.2 \\
\hline \multicolumn{9}{|l|}{ Marital status } \\
\hline Single & 46.7 & 22.3 & 25.9 & 43.2 & 50.1 & 36.9 & 44.4 & 20.0 \\
\hline Married & 53.0 & 76.1 & 71.8 & 56.8 & 46.4 & 51.2 & 46.2 & 69.3 \\
\hline Divorced/Widowed & .3 & 1.6 & 1.7 & 0 & 3.4 & 12.0 & 9.4 & 10.7 \\
\hline \multicolumn{9}{|l|}{ Age(Year) } \\
\hline Average & 34 & 40 & 38 & 36 & 33 & 32 & 34 & 34 \\
\hline \multicolumn{9}{|l|}{ Occupation } \\
\hline None & 4.3 & 2.3 & 1.5 & 3.8 & 2.0 & 8.0 & 4.3 & 2.1 \\
\hline Housewife & 16.0 & 4.5 & 4.9 & 15.6 & 15.5 & 6.9 & 26.2 & 9.9 \\
\hline Student & 41.7 & 13.3 & 12.5 & 34.6 & 28.9 & 23.1 & 31.6 & 17.6 \\
\hline Government official & 14.7 & 39.5 & 38.1 & 23.5 & 4.9 & 33.7 & 6.6 & 30.7 \\
\hline Employee & 12.7 & 7.1 & 16.3 & 6.0 & 23.8 & 18.9 & 21.1 & 4.2 \\
\hline Owner & 6.7 & 21.4 & 20.9 & 13.3 & 16.6 & 7.4 & 8.8 & 20.0 \\
\hline Agriculturist & 4.0 & 12.0 & 4.9 & 2.9 & 4.6 & 1.4 & 1.4 & 15.2 \\
\hline Others & 4.3 & 2.3 & .9 & .3 & 3.7 & 6 & 0 & .3 \\
\hline \multicolumn{9}{|l|}{ Education level } \\
\hline Below bachelor degree & 33.3 & 28.8 & 22.1 & 28.6 & 57.3 & 31.1 & 23.4 & 37.0 \\
\hline Bachelor degree & 60.3 & 61.8 & 65.4 & 54.0 & 40.1 & 59.4 & 66.4 & 55.5 \\
\hline Master degree & 6.0 & 8.1 & 10.2 & 16.5 & 2.3 & 8.9 & 10.0 & 7.5 \\
\hline Ph.D. & .3 & 1.3 & .3 & .3 & .3 & .6 & .3 & 0 \\
\hline
\end{tabular}




\begin{tabular}{lrrrrrrrr} 
Others & 33.3 & 28.8 & 2.0 & .6 & 0 & 0 & 0 & 0 \\
\hline Personal income(THB) & & & & & & & & \\
Min. & 0 & 0 & 0 & 0 & 0 & 0 & 0 & 0 \\
Max. & 35,000 & 80,000 & 80,000 & 80,000 & 70,000 & 70,000 & 35,000 & 35,000 \\
Average & 6,808 & 21,610 & 24,104 & 11,794 & 9,757 & 11,064 & 14,993 & 13,500 \\
\hline Householdincome(THB) & & & & & & & & \\
Min. & 5,000 & 4,500 & 5,000 & 7,500 & 5,000 & 7,500 & 12,500 & 12,500 \\
Max. & 45,000 & 100,000 & 100,000 & 100,000 & 100,000 & 75,000 & 55,000 & 75,000 \\
Average & 22,400 & 37,190 & 42,289 & 34,333 & 19,019 & 32,021 & 33,412 & 33,500 \\
\hline Trip purpose & & & & & & & & \\
Work & 19.7 & 12.3 & 11.0 & 27.3 & 18.1 & 15.4 & 14.8 & 15.2 \\
Business & 27.3 & 47.6 & 36.3 & 25.1 & 25.8 & 25.4 & 25.4 & 28.1 \\
Visiting family & 14.3 & 7.4 & 11.3 & 13.0 & 16.0 & 15.4 & 10.5 & 11.9 \\
Home & 26.3 & 1.9 & 4.4 & 16.5 & 7.7 & 33.1 & 34.2 & 38.5 \\
Touring & 12.0 & 27.2 & 32.0 & 13.0 & 8.3 & 10.6 & 13.4 & 6.3 \\
Study & .3 & 3.6 & 2.9 & 5.1 & 23.8 & 0 & 1.7 & 0 \\
Others & 0 & 0 & 2.0 & 0 & .3 & 0 & 0 & 0 \\
\hline
\end{tabular}

The results of this study showed the percentage of respondents' decision in choosing factors that determine their travel mode choice. In ST, main factors determining the choice of each mode were travel cost $(40 \%)$ and safety $(40 \%)$ for train. For bus, the dominant factors were travel cost $(20 \%)$, speed $(20 \%)$, convenience $(12 \%)$ and others $(12 \%)$. The dominant factors for air mode choice were speed $(38 \%)$, safety $(40 \%)$ and convenience $(20 \%)$. The factors influencing passengers travel by car were travel cost $(12 \%)$, speed $(36 \%)$ and convenience $(40 \%)$.

In HY, the results showed the dominant factors for train respondents were travel cost $(18 \%)$, speed $(20 \%)$, safety (38\%) and convenience (18\%). For bus, the dominant factors were speed $(36 \%)$, safety $(24 \%)$ and convenience $(32 \%)$. Air passengers' chosen factors which determined their mode choice were speed $(36 \%)$, safety $(28 \%)$ and convenience $(36 \%)$. For car mode, the main factors were speed $(28 \%)$, safety $(20 \%)$ and convenience (44\%). However, for health reasons, a small percentage of passengers chose to travel by bus and air mode in ST and train, bus and airplane in HY (see Fig. 11).

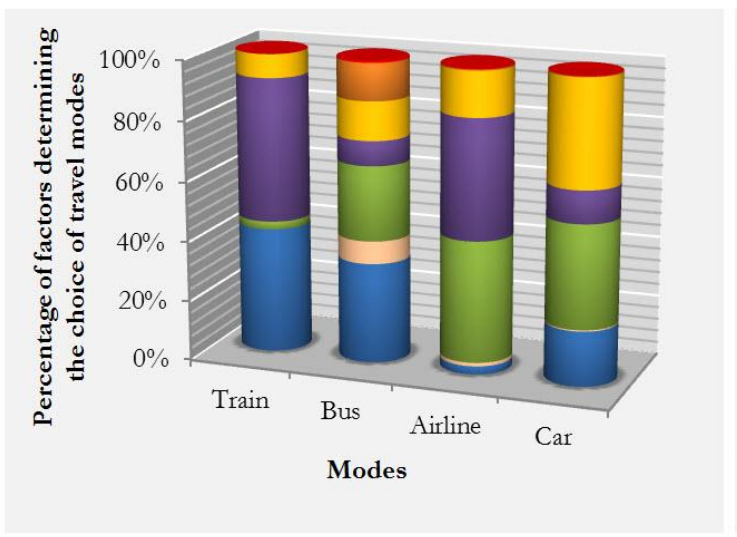

Surat Thani

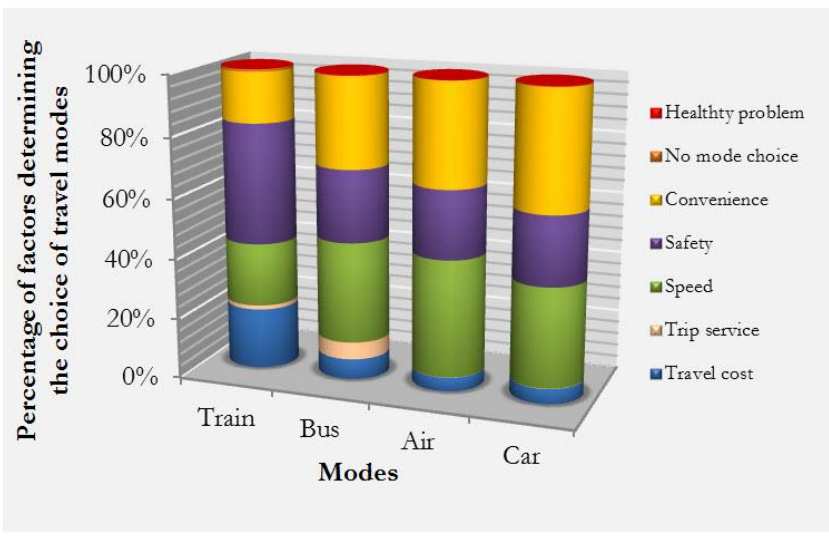

Hat-Yai city

Fig. 11. The percentage of factors determining the choice of travel modes in ST and HY.

Notwithstanding, in this study intercity travel can be separated into two modes: 1/public transport: train, bus and airplane where data on distance can be obtained for each pair of origin to destination and 2/ private mode: which includes cars and other passenger vehicles, e.g. pickups and vans whose destination depends on the travel purpose of respondents. Figure 12 showed relationship between number of car users and trip purpose classified by distance. 


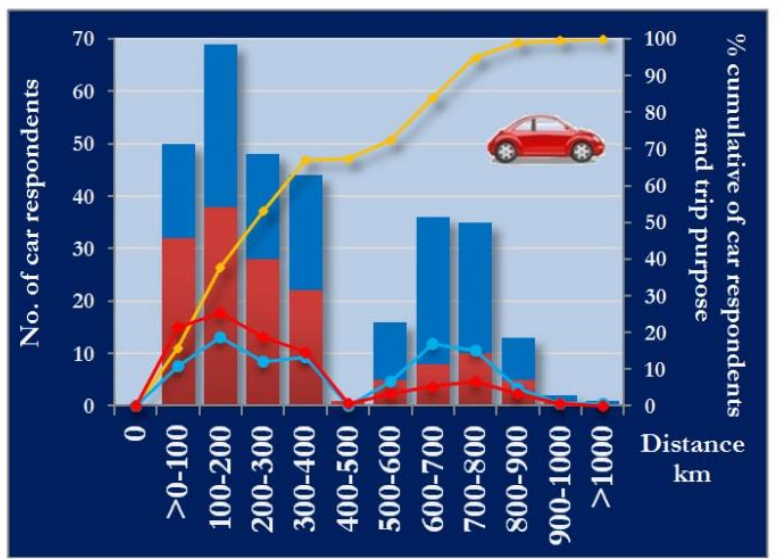

SuratThani

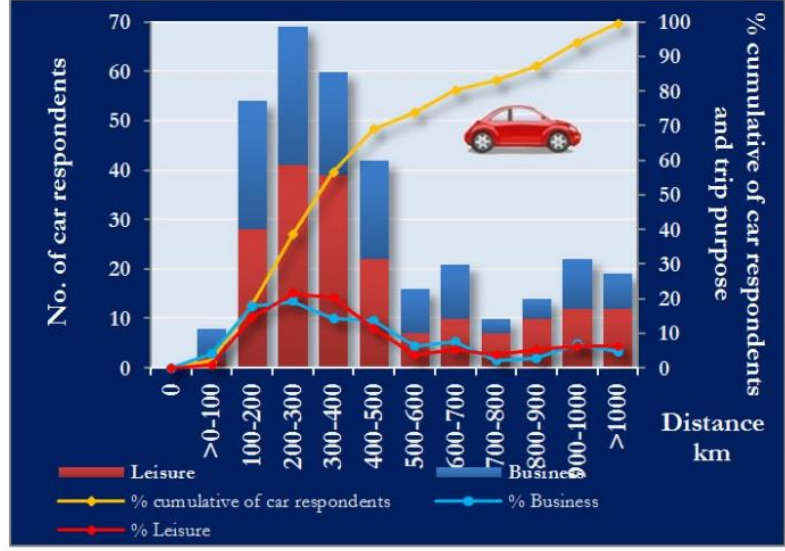

Hat-Yai city

Fig. 12. Relationship between number of car respondents and trip purpose classified by distance.

Most car users selected to travel short distance about $100-300 \mathrm{~km}$ (Over 50\%) from the origin and the number of car users gradually decrease after distance $300 \mathrm{~km}$ and increasing again at distance about 600 $-800 \mathrm{~km}$ in ST and $900-1,000 \mathrm{~km}$ in HY. Figure 12 showed distance which the number of car users increase again, in the range of $600-800 \mathrm{~km}$ and distance $900-1,000 \mathrm{~km}$ which is the distance between ST to Bangkok and HY to Bangkok, respectively. Consideration of the relationship between trip purposes and distance of ST show that for short distance, the main purpose of respondents was travelling for leisure and for long distance was travel for business. In HY, similarly for short distance but for long distance number of respondents selected same purpose about $10 \%$ of respondents in each purpose.

The 2010 OTP study of Thailand Master Plan for Transport and Traffic Development [22] has set the target for growth and mode share as follows: intercity public transport is to increase from $41 \%$ to $46 \%$ over the decade of the plan; reduction in private car use from $59 \%$ to $54 \%$; rail ridership is to be increased to $35 \%$ over the 12-year span (2007-2018). However, the government's emphasis on developing the rail mode, in particular, the double-track and the high-speed systems can be seen that the planned express train (120 $\mathrm{km} / \mathrm{h}$ on double track) will have a competitive edge over the bus and private car modes at travel distances of $200 \mathrm{~km}$ or longer. The HSR $(250 \mathrm{~km} / \mathrm{h})$ will rival the flying mode at distances about $600 \mathrm{~km}$. Given the prospects of such improvement, plus appropriate upgrades on the intercity rail systems, passengers will be accorded a better array of travel options which will help to discourage private car use and encourage their switching to the public modes, especially for travel distances over $200 \mathrm{~km}$.

\section{High Speed Rail Case Study}

\subsection{Competitiveness between modes}

As mentioned above in Fig. 9, travel time of express train with maximum speed $120 \mathrm{~km} / \mathrm{h}$ would have advantage over car at distance over $200 \mathrm{~km}$. However, for short and medium distance, HSR has advantage over all modes; on the other hand, air mode has advantage for longer distance. Given the competition between express train, HSR and car for short distance which showed travel time by car at a disadvantage but most car users chose to travel by this mode because of the greater convenience over other modes for short distances. Express train is at a disadvantage in competing with air mode for long distance as it takes much longer. HSR is a new mode choice which has potential to compete with air mode in medium distance. Factors that influence passengers' decision in choosing between HSR and air include not only travel time but also differences in fare. If airfare is more expensive, passengers will likely switch to HSR.

\subsection{Competitiveness between HSR vs. LCA and LCA vs. Intercity Rail}

As mentioned in sections 3.2 and 3.3, although the result showed car and intercity rail had advantagesover air at the same distance $(200 \mathrm{~km})$ but most car users selected to travel in short distance for the reason mentioned above. It can be mentioned that for medium to long distance, HSR can compete with air mode; 
however, intercity rail will still be able to compete with air due to the fact that market share of intercity rail comprises mostly of low income passengers.

It is clear that rail transport can play an important role for people wishing to travel medium to long distance. As shown in Fig. 9, policies for promoting multimodal transport, modal shares and travel demand should be adjusted to give a balanced multimodal transport development [22, 25]. HSR has an advantage over air for distance less than $550 \mathrm{~km}$ and intercity rail (on double track) has advantage over air for a short distance of $200 \mathrm{~km}$. Figure 13 shows critical distance for both: train vs. air $(204 \mathrm{~km})$ and HSR vs. air (568 $\mathrm{km})$. These are the intercepts where travel time between train and air is equal at $192 \mathrm{~min}$ or $3 \mathrm{hrs} 12 \mathrm{~min}$ and between HSR and air at $226 \mathrm{~min}$ or $3 \mathrm{hrs} 46 \mathrm{~min}$ from the origin. However, the results of O-D study show the average access \& egress times and terminal time for air $\left(\Delta T_{2}\right)$ are roughly similar to the access \& egress times and terminal time as calculated by linear regression model $\left(\Delta T_{1}\right)$ as shown in Table 5 . From the table, it is seen that air travel time is lower than travel time of HSR by only 1 hour for the O-D HY-BKK. This reflects the inefficient connection by public transport service from airport to city center. A better quality or seamless service is needed.

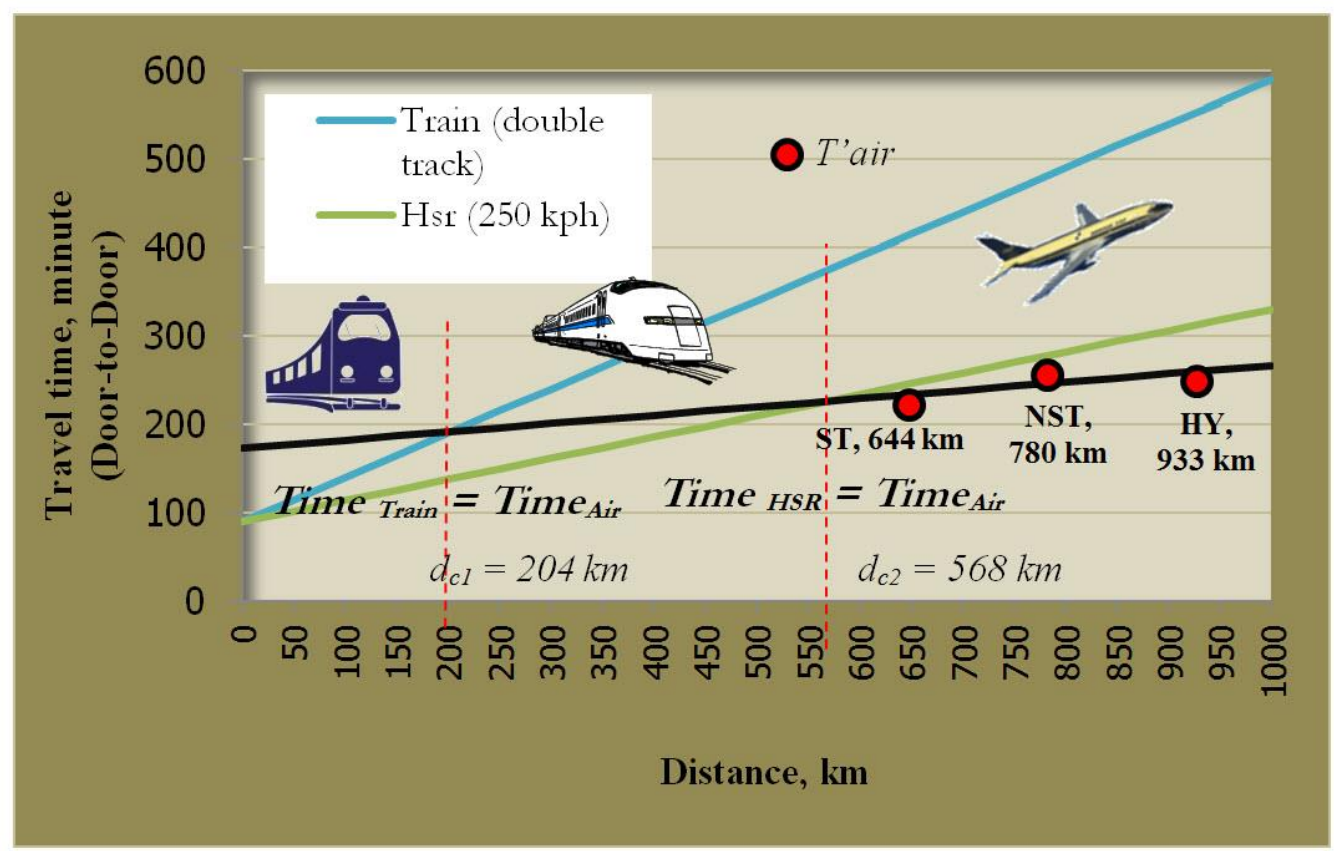

Fig. 13. Relationship of travel time and distance betweenHSR vs. LCA and intercity rail vs. LCA. Source: Calculated by authors.

Remark: $d_{c 1}$ and $d_{c 2}$ is critical distance which use equal travel time between two modes.

Table 5. Comparison between access \& egress time and terminal timeof O-D study and regression model of air mode.

\begin{tabular}{|c|c|c|c|c|c|c|c|c|}
\hline \multirow[b]{2}{*}{ O-D } & \multirow[b]{2}{*}{$\begin{array}{c}\text { In - } \\
\text { vehicle } \\
\text { time of } \\
\text { air } \\
\left(F_{I V T}\right) \\
\text { min }\end{array}$} & \multirow[b]{2}{*}{$\begin{array}{c}\text { Travel } \\
\text { time by } \\
\text { regression } \\
\text { model* } \\
\left(T_{a i r}\right) \\
\text { min }\end{array}$} & \multirow[b]{2}{*}{$\begin{array}{c}\Delta T_{1}= \\
T_{a i r}-F_{I V T} \\
\quad \min \end{array}$} & \multicolumn{2}{|c|}{$\left.\left.\Delta T_{2}=1\right)+2\right)$} & \multirow[b]{2}{*}{$\begin{array}{l}\boldsymbol{\Delta} \boldsymbol{T}_{2} \\
\min \end{array}$} & \multirow[b]{2}{*}{$\begin{array}{l}\text { Average } \\
\text { O-D travel } \\
\text { time } \\
T_{\text {air }}^{,}=F_{I V T} \\
+\Delta T_{2} \\
\text { min }\end{array}$} & \multirow[b]{2}{*}{$\begin{array}{c}\text { Travel } \\
\text { time of } \\
\text { HSR** } \\
\text { min }\end{array}$} \\
\hline & & & & $\begin{array}{l}\text { 1)Access } \\
\text { \&Egress } \\
\text { time } \\
\text { by O-D } \\
\text { study } \\
\text { min }\end{array}$ & $\begin{array}{l}\text { 2)Terminal } \\
\text { time } \\
\text { by } \\
\text { O-D study } \\
\text { min }\end{array}$ & & & \\
\hline ST-BKK & 60 & 233.51 & 173.5 & 85.23 & 87.61 & 172.8 & 232.84 & 244.56 \\
\hline NST-BKK & 80 & & 166.32 & 87.73 & 84.41 & 172.14 & 252.14 & 277.20 \\
\hline HY-BKK & 90 & 260.73 & 170.73 & 75.21 & 79.65 & 154.86 & 244.86 & 313.92 \\
\hline
\end{tabular}

\footnotetext{
Remark: *The regression model for air: $\mathrm{Y}_{\text {air }}=0.0942 \mathrm{X}+172.84$

**The regression model for HSR: $\mathrm{Y}_{\mathrm{HSR}}=0.24 \mathrm{X}+90$

$\mathrm{Y}=$ Travel time (min.), $\mathrm{X}=$ Distance $(\mathrm{ST}=644 \mathrm{~km}, \mathrm{NST}=780 \mathrm{~km}$ and $\mathrm{HY}=933 \mathrm{~km})$.
} 


\subsection{Model Results of Competition}

As shown in Fig. 13, O-D survey between HY-BKK indicates a high potential for competition between HSR vs. LCA and Intercity rail vs. LCA. Discrete choice model was selected to analyze and predict a decision maker's factorswhich determine the choice of one of alternatives mode of HSR, LCA or intercity rail [26]. The random utility theory was used for explaining choice behavior and stated preference (SP) technique was used to design questionnaire for non-existing market situations. The SP experiments were designed for three modes (Intercity rail, HSR and LCA) with three attributes and two levels of travel time and frequency and three levels of travel cost in each mode (see in Table 6). A total of 8 scenarios were created by SPSS program version 20 to generate all the attributes which were independent and orthogonal. Examples of card of SP choice scenario are shown in Table 7.

Table 6. Attributes and levels for alternative modes.

\begin{tabular}{lrrrrrrr}
\hline \multirow{3}{*}{ Mode } & \multicolumn{7}{c}{ Attribute } \\
\cline { 2 - 8 } & \multicolumn{1}{c}{ Travel time (hr:min) } & \multicolumn{2}{c}{ Frequency (trains/day) } & \multicolumn{2}{c}{ Fare (THB) } \\
\cline { 2 - 8 } & Level 1 & Level 2 & \multicolumn{1}{c}{ Level 1 } & Level 2 & Level 1 & Level 2 & Level 3 \\
\hline Intercity rail & $9: 30$ & $11: 50$ & 20 & 15 & 945 & 1,134 & 1,230 \\
HSR & $4: 40$ & $5: 15$ & 20 & 15 & 1,420 & 1,500 & 1,600 \\
LCA & $3: 10$ & $3: 40$ & 7 & 9 & 1,760 & 2,030 & 3,300 \\
\hline
\end{tabular}

Remark: Adapted from recommendation made by OTP, 2010.

Table 7. Example of card of choice scenario.

\begin{tabular}{lccc}
\hline \multicolumn{1}{c}{ Case 1 } & $\begin{array}{c}\text { Intercity rail } \\
\text { (double track) }\end{array}$ & $\begin{array}{c}\text { HSR } \\
250 \mathrm{kph}\end{array}$ & LCA \\
\hline Travel time (hr:min) & $11: 50$ & $4: 40$ & $3: 40$ \\
Frequency & every 15 min & every 20 min & 9 flights/day \\
Fare (THB) & 945 & 1,500 & 3,300 \\
Which mode would you prefer? & 0 & 0 & 0 \\
\hline \multicolumn{1}{c}{ Case 5 } & Intercity rail & HSR & LCA \\
& (double track) & $250 \mathrm{kph}$ & \\
\hline Travel time (hr:min) & $9: 30$ & $5: 15$ & $3: 10$ \\
Frequency & every 20 min & every 15 min & 7 flights/day \\
Fare (THB) & 1,134 & 1,600 & 1,760 \\
Which mode would you prefer? & 0 & 0 & 0 \\
\hline
\end{tabular}

The regression logit model is selected to forecast modal split based on random utility theory. Independent variables are considered for utility function such as travel time, frequency, and fare and socioeconomic of each respondent. The logit model and modal competition between modes are as shown below:[27]

$$
P_{i q}=\frac{e^{V_{i q}}}{\sum_{j=1}^{k} e^{V_{j q}}}
$$

where $\quad P_{i q}=$ Probability of the $i$ th alternative for the $q$ th individual

$V_{i q}=U_{i q}-\varepsilon_{i q}$

$V_{i q}=\Sigma \beta_{j k} X_{i k q}$

$U_{i q}=$ the utility of the $i$ th alternative for the $q$ th individual

$V_{i q}=$ Representative utility

$\varepsilon_{i q}=$ A random component

$X_{i k q}=$ Set of vectors of measured attributes of the decision makers

$$
\begin{gathered}
V_{T}=\beta_{1} T R V T_{T}+\beta_{2} T_{R V F_{T}+\beta_{3} T R V C_{T}+\gamma_{i} Z_{i}} \\
V_{H}=A S C_{1}+\beta_{1} T R V T_{H}+\beta_{2} T R V F_{H}+\beta_{3} T R V C_{H}+\gamma_{i} Z_{i} \\
V_{A}=A S C_{2}+\beta_{1} T R V T_{A}+\beta_{2} T R V F_{A}+\beta_{3} T R V C_{H}+\gamma_{i} Z_{i}
\end{gathered}
$$




where $\quad \begin{array}{ll}V_{T} & =\text { Utility function of intercity rail mode } \\ V_{H} & =\text { Utility function of high speed rail } \\ V_{A} & \text { Utility function of low cost carrier } \\ A S C_{1,2}= & \text { Alternative specific constant } \\ \beta_{i}= & \text { Utility parameter of independent variables } \\ \gamma_{i}= & \text { Utility parameter of socio-economic variables } \\ T R V T_{i}= & \text { Travel time of alternative mode } \\ T R V F_{i}= & \text { Trip frequency service of alternative mode } \\ T R V C_{i}= & \text { Mode fare } \\ Z_{i}= & \text { Independent variables of socio-economic of respondentsincluding personal } \\ & \text { income (PINC), household income (HINC), household member (HMEM), } \\ & \text { household worker (HWORK), trip purpose (PURPOSE, coded 0 = Leisure, } \\ & =\text { Business), frequency of trip demand (FREQ), number of co-traveller } \\ & \text { (NTRV), sex (GENDER, coded } 0=\text { Female, } 1=\text { Male) and education level } \\ & \text { (EDU, coded } 0=\text { Otherwise, } 1=\text { Bachelor degree) }\end{array}$

Table 8 shows the model results of estimated factors which determine mode choice of HSR, LCA and intercity rail. Logit models were analyzed using Limdep program version 9 and the result of both models were shown: the first model shows input of all variables, the other shows input of correct signs of utility parameters. For the models, negative sign are associated with travel time, travel cost, number of household member, frequency of trip demand due to increasing of utility when these factors decrease. Positive sign are associated with travel frequency service, personal income, and household income, number of household worker because the utility will be increased following the sigh of these factors [28].

Model-2 shows the results of the best fitted model because all variables are found to be statistically significant in explaining the mode choice behavior. Both of alternative specific constant of LCA (ASC-1) and HSR (ASC-2) show positive sigh and ASC-2 value is more than ASC-1. This shows that respondents prefer the utility of HSR choice rather than LCA choice when compared with intercity rail. Utility function for the three models are shown below.

$$
\begin{aligned}
& V_{T}=-.0003(T R V C)_{T} \\
& V_{H}=2.031-.0003(\text { TRVC })_{H}+.266 \mathrm{E}-04(\text { HINC) }-.244 \text { (PURPOSE) }-.276(\text { NTRV })-.351 \text { (EDU) } \\
& V_{A}=.426-.0003(\text { TRVC })_{A}+.329 \mathrm{E}-04(\text { HINC) }-.369 \text { (PURPOSE) }-.491 \text { (NTRV) - .489 (EDU) } \\
& V_{A}-V_{T}=.426-.0003\left(T R V C_{A}-T R V C_{T}\right)+.329 \mathrm{E}-04(H I N C)-.369 \text { (PURPOSE) - .491(NTRV) } \\
& -.489(E D U) \\
& V_{H}-V_{A}=1.605-.0003\left(T R V C_{H}-T_{R} V C_{A}\right)-.063 \mathrm{E}-04(H I N C)+.125 \text { (PURPOSE) }+.215(N T R V) \\
& +.213(E D U)
\end{aligned}
$$

Factors influencing utility models are fare, household income, trip purpose, number of co- traveler and education level. The individual utility model shows that respondents prefer travel by HSR more than other modes because ASC of HSR has the highest value. The relation of the utility of LCA and intercity rail shows positive sigh for constant and household income variable and negative sigh for trip purpose, number of co-traveler and education level. This shows that if respondents have more household income, they prefer travel by LCA, on other hand, when the number of co-travellers increase, the utility of air decreases. The utility of air decreases if respondents select to travel for leisure. While the utility of HSR relative to that of LCA has a negative coefficient of household income, this is because as the respondents have more income, the utility of LCA increases.

Table 8. Model results.

\begin{tabular}{lrrrr}
\hline \multirow{2}{*}{ Variable } & \multicolumn{2}{c}{ Model-1 } & \multicolumn{2}{c}{ Model-2 } \\
\cline { 2 - 5 } & \multicolumn{1}{c}{ Coefficient } & t-statistic & Coefficient & t-statistic \\
\hline TRVT & .0014 & $4.037^{*}$ & - & - \\
TRVF & -.0199 & $-3.172^{*}$ & - & - \\
TRVC & -.0002 & $-4.984^{*}$ & -.0003 & $-5.405^{*}$ \\
ASC1 & -.6866 & $-2.405^{*}$ & .4259 & $2.711^{*}$ \\
AIR_PINC & $-.7125 \mathrm{E}-04$ & $-12.202^{*}$ & - & - \\
AIR_HINC & $.7566 \mathrm{E}-04$ & $10.169^{*}$ & $.3288 \mathrm{E}-04$ & $-5.842^{*}$ \\
AIR_HMEM & .3693 & $11.167^{*}$ & - & - \\
AIR_HWORK & -.2590 & $-3.906^{*}$ & - & -
\end{tabular}




\begin{tabular}{|c|c|c|c|c|}
\hline AIR_PURPOSE & -.2751 & $-3.113^{*}$ & -.3694 & $-4.276^{*}$ \\
\hline AIR_FREQ & .0070 & .711 & - & - \\
\hline AIR_NTRV & -.3730 & $-7.968^{*}$ & -.4905 & $-10.888^{*}$ \\
\hline AIR_GENDER & -.0777 & -.872 & - & - \\
\hline AIR_EDU & .1307 & 1.415 & .4887 & $5.604^{*}$ \\
\hline ASC $\overline{2}$ & 1.6276 & $8.097 *$ & 2.0310 & $17.688^{*}$ \\
\hline HSR_PINC & $-.6147 \mathrm{E}-04$ & $-12.941 *$ & - & - \\
\hline HSR_HINC & $.6346 \mathrm{E}-04$ & $10.379 *$ & $.2611 \mathrm{E}-04$ & $5.740^{*}$ \\
\hline HSR_HMEM & .2662 & $9.594^{*}$ & - & - \\
\hline HSR_HWORK & -.2644 & $-5.843^{*}$ & - & - \\
\hline HSR_PURPOSE & -.1651 & $-2.359 *$ & -.2435 & $-3.579 *$ \\
\hline HSR_FREQ & .0010 & .128 & - & - \\
\hline HSR_NTRV & -.1751 & $-5.217 *$ & -.2760 & $-8.869 *$ \\
\hline HSR_GENDER & -.1350 & $-1.894 *$ & - & - \\
\hline HSR_EDU & .0668 & .909 & .3509 & $5.086^{*}$ \\
\hline Number of cases & & & & \\
\hline$L L\left(\beta^{*}\right)$ & -692 & & -714 & \\
\hline $\operatorname{LL}(0)$ & -728 & & -728 & \\
\hline${ }^{* *} \operatorname{LR}\left(\chi^{2}\right)$ & 710.7 & & 289.5 & \\
\hline$\rho^{2}$ & & & & \\
\hline Pseudo $\rho^{2}$ & & & & \\
\hline
\end{tabular}

Remark: *significant at the 5 percent level. $* *\left(\mathrm{H}_{\mathrm{o}}\right.$ : all $\beta$ are 0$)$.

\subsection{Willingness To Pay and Model Results for HSR Fare}

The number of domestic passengers of Low Cost Airlines grew from 14.37 million to 26.32 million over the 10 year period, 1999-2009. Full Cost Airline market share were significantly reduced on most of all routes due to the cheaper of LCA fares. The data of one way LCA fares from Bangkok to six provinces in the south region, at seven days before departure, during 18 - 24 May 2012 are shown in Table 9. The data show the average fare is about $2.65 \mathrm{THB} / \mathrm{km}$ (US\$ 0.09 per $\mathrm{km}$ ).

Table 9. Distance from Bangkok, fare $/$ seat and fare $/ \mathrm{km}$ of LCA of six provinces in the south region.

\begin{tabular}{|c|c|c|c|c|c|}
\hline \multirow[t]{2}{*}{ Provinces } & \multirow{2}{*}{$\begin{array}{c}\text { Distance } \\
\mathrm{km}\end{array}$} & \multicolumn{2}{|c|}{ Fare/seat* } & \multicolumn{2}{|c|}{ Fare $/ \mathrm{km}$} \\
\hline & & THB & US\$ & $\mathrm{THB} / \mathrm{km}$ & $\mathrm{US} \$ / \mathrm{km}$ \\
\hline Surat Thai & 520 & 1,580 & 52.7 & 3.04 & 0.10 \\
\hline Nakhon Si Thammarat & 590 & 1,580 & 52.7 & 2.68 & 0.09 \\
\hline Krabi & 645 & 1,830 & 61.0 & 2.84 & 0.10 \\
\hline Trang & 682 & 1,670 & 55.7 & 2.45 & 0.08 \\
\hline Phuket & 684 & 1,670 & 55.7 & 2.44 & 0.08 \\
\hline Hat-Yai & 735 & 1,800 & 60.0 & 2.45 & 0.08 \\
\hline Average & & & & 2.65 & 0.09 \\
\hline
\end{tabular}

Remark: *LCA fare is for booking 7 days before departure during 18-24 May 2012.

On $15^{\text {th }}$ April 2012, Thailand and China have agreed to sign a memorandum of understanding to conduct a feasibility study for the northern corridor and northeastern corridor of HSR routes [29]. The study by the Chinese team recommended HSR fare for the $250 \mathrm{~km} / \mathrm{h}$ train at $2.1 \mathrm{THB} / \mathrm{km}(\mathrm{US} \$ 0.07 / \mathrm{km})$ and for the $300 \mathrm{~km} / \mathrm{h}$ at $2.5 \mathrm{THB} / \mathrm{km}$ (US\$ $0.08 / \mathrm{km}$ ), as mentioned in the introduction. The gap between the higher LCA fare and the $250 \mathrm{~km} / \mathrm{h}$ HSR fare is a difference of $29 \%$; and for the $300 \mathrm{~km} / \mathrm{h}$ HSR, it is $11 \%$. However, the O-D case study of Willingness-To-Pay (WTP) in the southern corridor between STBKK and HY-BKK are for analyzing the factors which determine the mean W'TP comparing between LCAand HSR fares and the recommended fares.

The sample sizes were the same as in section 3.3. The questionnaires were divided into two sections of the equation: socioeconomic and bid fare amount. WTP was evaluated with Contingent Valuation Methods (CVM) and was estimated using a double bounded dichotomous model. Regression logit model was selected to analyze the influence WTP variables. The regression logit model is specified as

$$
Y=\alpha+\beta_{1} X_{1}+\beta_{2} X_{2}+\ldots \ldots . . \beta_{i} X_{i}
$$


where $Y=$ Logit (WTP) responses of WTP HSR fare which is either 1 for Yes and 0 for No

$\alpha=Y$ intercept

$\beta_{i}=$ the coefficient of independent variables

$X_{1}=$ Gender $(\operatorname{coded} 0=$ Female, $1=$ Male $)$

$X_{2}=$ Marital status (coded $0=$ Married, $1=$ Single)

$X_{3}=$ Age (in ranges)

$X_{4}=$ Occupation $($ coded $0=$ Otherwise, $1=$ Student $)$

$X_{5}=$ Occupation (coded $0=$ Otherwise, $1=$ Government official)

$X_{6}=$ Occupation $($ coded $0=$ Otherwise, $1=$ Employee $)$

$X_{7}=$ Occupation (coded $0=$ Otherwise, $1=$ Owner)

$X_{8}=$ Education level (coded $0=$ Otherwise, $1=$ Bachelor degree)

$X_{9}=$ Personal income per month (in ranges)

$X_{10}=$ Household income per month (in ranges)

$X_{11}=$ Trip purposes (coded $0=$ Leisure, $1=$ Business)

$X_{12}=$ Initial bid amount

Initial bid amount were determined by pilot test with 30 sets of questionnaire in each modes of each OD pair. Respondents were free to offer HSR fare by open bid and initial bid amount was selected from the four highest frequencies of respondents. The initial bid amounts of O-D ST-BKK were 500, 600, 950 and 1,500 Baht and the initial bid amounts of O-D HY-BKK were 950, 1,000, 1,200 and 1,500 Baht.

Mean WTP can be calculated using formula derived by and given as [30]:

$$
\text { Mean_WTP }=\frac{1 * \ln \left(1+e^{\alpha}\right)}{\left|\beta_{\text {bid }}\right|}
$$

where: $\ln$ is the natural logarithm and $\beta_{\text {bid }}$ is absolute coefficient of initial bid amount.

The model result shows that factors which determine the HSR fare for O-D pair ST-BKK at 95\% confidence levelcomprise occupation variables, education level, household income and initial bid amount. For O-D pair HY-BKK, the determining factors are education level, household income, trip purposes and initial bid amount (see Table 10). Mean WTP models for ST and HY are as shown below:

WTP for HSR fare for ST-BKK route:

$$
\begin{aligned}
& Y_{S T}=5.5273-1.0663 X_{4}-1.0334 X_{5}-1.1941 X_{6}-1.3544 X_{7} \\
& +.5132 X_{8}+.00002 X_{10}-.0047 X_{12}
\end{aligned}
$$

W'TP for HSR fare of HY-BKK route:

$$
Y_{H Y}=6.4454+.4914 X_{8}+.00004 X_{10}-.2964 X_{11}-.0046 X_{12}
$$

Mean WTP HSR fare for ST and HY were calculated using Eq. (6) which gave the results as 1,177 THB (US\$39.2) or $1.8 \mathrm{THB} / \mathrm{km}$ (US\$ $0.06 / \mathrm{km}$ ) for ST-BKK and $1,402 \mathrm{THB}$ (US $\$ 46.7$ ) or $1.5 \mathrm{THB} / \mathrm{km}$ (US $\$ 0.05 / \mathrm{km}$ ) for HY-BKK. The average HSR fare in southern corridor then is $1.65 \mathrm{THB} / \mathrm{km}$ (US\$ 0.06 $/ \mathrm{km}$ ) and this shows that WTP for HSR fare is significantly lower than the recommended fare proposed by the Chinese study team of $2.10 \mathrm{THB} / \mathrm{km}$ (US $\$ 0.07 / \mathrm{km}$ ). Although the result of this study shows that HSR has an advantage over LCA in terms of fare difference but LCA has advantage over HSR for travel time (see Table 11). However, the current strategy of LCA is the promotion of cheap fares in low seasons which can help keep the market share in competition with other modes.

Table 10. Determinants of HSR fare of O-D pairs: ST-BKK and HY-BKK.

\begin{tabular}{lrrrrrr}
\hline & \multirow{2}{*}{ Variables } & \multicolumn{3}{c}{ ST-BKK } & \multicolumn{3}{c}{ HY-BKK } \\
\cline { 2 - 7 } & \multicolumn{1}{c}{$\beta_{i}$} & \multicolumn{1}{c}{ p-value } & Exp $\left(\beta_{i}\right)$ & \multicolumn{1}{c}{$\beta_{i}$} & \multicolumn{1}{c}{$p$-value } & Exp $\left(\beta_{i}\right)$ \\
\hline$\alpha$ & 5.5273 & .0000 & - & 6.4454 & .0000 & - \\
$X_{1}$ & -.3103 & .0883 & .7332 & -.0926 & .5390 & .9116 \\
$X_{2}$ & .5929 & .0737 & 1.8092 & - & - & - \\
$X_{3}$ & - & - & - & - & - & - \\
$X_{4}$ & -1.0663 & .0116 & .3443 & -.4185 & .0789 & .6580 \\
$X_{5}$ & -1.0334 & .0011 & .3557 & -.3435 & .2845 & .7093 \\
$X_{6}$ & -1.1941 & .0019 & .3029 & -.1071 & .7134 & .8984 \\
$X_{7}$ & -1.3544 & .0002 & .2580 & -.7541 & .0610 & .4704 \\
$X_{8}$ & .5133 & .0139 & 1.6707 & .4914 & .0118 & 1.6346 \\
$X_{9}$ & $.2650 \mathrm{E}-05$ & .7846 & 1.0000 & $-.1730 \mathrm{E}-04$ & .1999 & 1.0000 \\
$X_{10}$ & $.1548 \mathrm{E}-04$ & .0188 & 1.0000 & $.3557 \mathrm{E}-04$ & .0053 & 1.0000
\end{tabular}




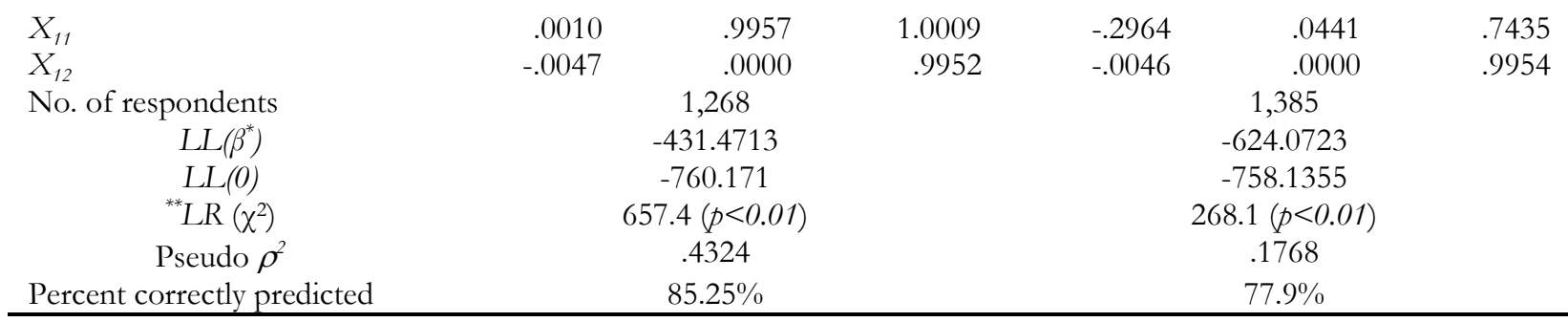

Table 11. Comparison of HSR fare among O-D case study, OTP recommendation, Chinese feasibility study and low cost airlines farein Thailand and other countries.

\begin{tabular}{|c|c|c|c|c|c|c|}
\hline \multirow{2}{*}{$\begin{array}{c}\text { Origin- } \\
\text { Destination }\end{array}$} & \multirow{2}{*}{$\begin{array}{l}\text { Travel time } \\
\text { (h:min) }\end{array}$} & \multicolumn{2}{|c|}{ Fare } & \multicolumn{2}{|c|}{ Fare $/ \mathrm{km}$} & \multirow{2}{*}{ Remarks } \\
\hline & & THB & US\$ & THB & US\$ & \\
\hline ST-BKK & $3: 53$ & 1,177 & 39.2 & 1.80 & 0.06 & From O-D case study \\
\hline HY-BKK & 4:05 & 1,402 & 46.7 & 1.50 & 0.05 & \\
\hline Average & - & - & - & 1.65 & 0.06 & \\
\hline HSR $250 \mathrm{~km} / \mathrm{hr}$ & $4: 14^{*}$ & - & - & 1.60 & 0.05 & OTP recommendation \\
\hline HSR $250 \mathrm{~km} / \mathrm{hr}$ & $4: 14^{*}$ & - & - & 2.10 & 0.07 & From the Chinese report \\
\hline HSR $300 \mathrm{~km} / \mathrm{hr}$ & N.A. & - & - & 2.50 & 0.08 & \\
\hline HSR in Japan & $2: 39$ & 4,230 & 141 & 7.80 & 0.26 & Tokyo-Osaka (Nozomi) \\
\hline HSR in China & $7: 56$ & 1,950 & 65 & 1.80 & 0.06 & Beijing-Shanghai $(250 \mathrm{~km} / \mathrm{h})$ \\
\hline HSR in Europe & $2: 38$ & 2,220 & 74 & 3.60 & 0.12 & Madrid-Barcelona (AVE) \\
\hline Average of LCA & - & - & - & 2.65 & 0.09 & Six provinces in the south of Thailand \\
\hline LCA in Japan & - & 7,380 & 246 & 13.50 & 0.45 & Tokyo-Osaka (Nozomi) \\
\hline LCA in China & - & 12,330 & 411 & 9.30 & 0.31 & Beijing-Shanghai $(250 \mathrm{~km} / \mathrm{h})$ \\
\hline LCA in Europe & - & 4,950 & 165 & 8.10 & 0.27 & Madrid-Barcelona (AVE) \\
\hline
\end{tabular}

Note: *O-D between HY-BKK; N.A. = Not Available.

\section{Conclusions}

In the current study O-D pairs between ST to BKK and HY to BKK were selected because the two cities lie on the planned HSR route for southern corridor. The results show most passengers in ST chose to travel by train, while those in HY chose air transport. Car respondents chose to travel short distance for leisure purpose and long distance for business purpose. The utility model of competition shows that the likelihood ration $(L R)$ is statistically significant with a $\chi^{2}$ statistic of 289.5 at $99 \%$ confidence level $(p<0.001)$ and rejected the null hypothesis (all coefficient of independent variables are zero).

The study of WTP for HSR fare the ST-BKK and HY-BKK routes show that the likelihood ration (LR) is statistically significant with a $\chi^{2}$ statistic of 657.4 and 268.1 at $99 \%$ confidence level $(p<0.001)$, respectively. The mean WTP for HSR fare of ST-BKK is 1,177 THB (US\$ 39.2) or $1.8 \mathrm{THB} / \mathrm{km}$ (US\$ $0.06 / \mathrm{km}$ ) and $1,402 \mathrm{THB}$ (US\$46.7) or $1.5 \mathrm{THB} / \mathrm{km}(\mathrm{US} \$ 0.05 / \mathrm{km}$ ) for HY-BKK. The average HSR fare in southern corridor is $1.65 \mathrm{THB} / \mathrm{km}$ (US\$ $0.06 / \mathrm{km})$ which is less than the recommended fare of 2.1 $\mathrm{THB} / \mathrm{km}$ (US $\$ 0.07 / \mathrm{km}$ ) as proposed by the Chinese study team. This study concludes that competitiveness between HSR and LCA depends not only on travel time but also on factors such as fare difference, users'occupation, household income, education level and trip purposes. Given the average fare for LCA for the southern corridor at $2.65 \mathrm{THB} / \mathrm{km}$, compared with the average HSR fare of 1.65 $\mathrm{THB} / \mathrm{km}$, it is seen that the fare differential of $1 \mathrm{THB} / \mathrm{km}(\mathrm{US} \$ 0.03 / \mathrm{km})$ could be significant in making passengers change from LCA to HSR, thus giving the HSR the competitive edge over LCA. 


\section{Acknowledgements}

The authors express their deep gratitude to Professor Dr. Shigeru Morichi and Professor Dr. Surya Raj Acharya for the invitation to participate in this important international collaborative research project on Asian intercity transport, and the valuable advice. They are grateful to the Institute for Transport Policy Studies (ITPS) Tokyo, Japan for the funding support to conduct the survey and to attend many meetings and conferences.

\section{References}

[1] Department of Civil Aviation (DCA). 2010. [Online]. Available: http://www.aviation.go.th. [Accessed: 29 March 29 2012].

[2] Office of Transport and Traffic Policy and Planning, "Thailand Master Plan for Development of Double Track Rail and High-Speed-Rail”, Bangkok, Thailand, 2010.

[3] Bangkokpost. (2012). China Pitches Ayutthaya as First High Speed Rail Stop. [Online]. Available: http://www.bangkokpost.com/news/local/325255/china-pitches-ayutthaya-as-first-high-speed-railstop [Accessed: 15 January 2013].

[4] Bangkokpost. (2013). Infrastructure Bill Sails through Government Plans Special May Session to Fast-Track Law. [Online]. Available: http://www.bangkokpost.com/news/politics/ 343054/infrastructure-bill-sails-through [Accessed: 30 March 2013].

[5] International Union of Railways (UIC). (2013). High Speed Lines in the World. Available http://www.uic.org/spip.php?article573. [Accessed: 2 May 2013].

[6] L. Zhou and Z. Shen, "Progress in high speed train technology around the world," Journal of Modern Transportation, vol. 19, no. 1, pp. 1-6, March 2011.

[7] M. Neala. (2012). China-ASEAN High-Speed Rail Project. Undergraduate Review [Online]. 8, pp. 135-138. Available: http://vc.bridgew.edu/undergrad_rev/vol8/issl/24 [Accessed: 15 January 2013].

[8] R. Bullock, A. Salzberg, and Y. Jin, "High-Speed-Rail-The first three years: Talking the pulse of China's emerging program Feburary 2012," China Transport Topics No.4, World Bank office, Beijing.

[9] Global Times. (2013). Beijing-Shanghai high-speed railway records $100 \mathrm{mln}$ passenger trips [Online]. Available: http://www.globaltimes.cn/content/764922.shtml [Accessed: 19 May 2013].

[10] W. Wang (2011). Airlines cut fares to Beijing [Online]. Available: http://www.shanghaidaily.com/nsp/National/2011/06/28/Airlines\%2Bcut $\% 2$ Bfares $\% 2 B t o \% 2 B B e i j$ ing/ [Accessed: 20 May 2013].

[11] B. Albalate and G. Bel, "High-Speed Rail: Lessons for policy makers from experiences abroad," Research of Institute of Applied Economics, Universitat de Barcelona., Barcelona, Spain, 2010.

[12] International Union of Railways (UIC). (2013). High Speed Maps [Online]. Available: http://www.uic.org/IMG/jpg/carte_monde_2012_pts_jaune.jpg [Accessed: 2 May 2013].

[13] Y. Freemark. (2010). China Promotes Its Transcontinental Ambitions with Massive Rail Plan. The Transport Politic [Online]. Available: http://www.thetransportpolitic.com/2010/03/09/chinapromotes-its-transcontinental-ambitions-with-massive-rail-plan/ [Accessed: 2 May 2013].

[14] International Union of Railways (UIC). (2013). High Speed Maps [Online]. Available http://www.uic.org/spip.php?article2727 [Accessed: 2 May 2013].

[15] S. Y. Lee. (2007). A study of the development and issues concerning high speed rail. Woking paper no. 1020. Transport Studies Unit. Oxford University Center of the Environment [Online]. Available: http://www.tsu.ox.ac.uk/ [Accessed: 20 May 2013].

[16] R. Sakamoto, (2012). High speed railway productivity: A global study and potential for the US northeast corridor. US Transportation Productivity Study. Massachusetts Institute of Technology, USA.

[17] European Commission. (2012). EU Transport in Figures, Statistical Pocketbook 2012 [Online]. Available: http://europa.eu [Accessed: 2 November 2012].

[18] Y. M. Chang, et al., "The future of intercity passenger transportation," School of Public and Environmental Affairs, Indiana University, USA, 2011.

[19] Y. Freemark. (2010). Getting the prices right: How much should high-speed fares cost? The Transport Politic [Online]. Available: http://www.thetransportpolitic.com/2009/09/08/getting-the-price-righthow-much-should-high-speed-fares-cost/. [Accessed: 20 May 2013]. 
[20] I. Barron, J. Campos, P. Gagnepain, C. Nash, A. Ulied, and R. Vickerman, Economic Analysis of High Speed Rail in Europe. Gines de Rus, Ed. BBVA Foundation, University of Las Palmas of Gran Canaria, Spain, 2009.

[21] Office of Transport and Traffic Policy and Planning, "Thailand intercity public transport study," Bangkok, Thailand, Final Rep., 2009.

[22] Office of Transport and Traffic Policy and Planning, "Thailand Master Plan for Transport and Traffic Development," Bangkok, Thailand, Draft Final Rep., 2010.

[23] Ministry of Transport, "Draft of thailand high speed rail standard specification," Thailand, 2011.

[24] Office of Transport and Traffic Policy and Planning, "Thailand master plan for transport and traffic development," Bangkok, Thailand, 2010.

[25] ITPS, "Concept note of an international collaborative transport research," 2010.

[26] F. Koppelman and C. Bhat, "A self instructing course in mode choice modeling: Multinomial and nested logit models," U.S. Department of Transportation Federal Transit Administration, 2006.

[27] M. E. Ben-Akiva and S. Lermam, Discrete Choice Analysis: Theory and Application to Travel Demand. Cambridge, Mass.: MIT Press, 1985.

[28] J. Louviere, D. A. Hensher, and J. Swait, Stated Choice Methods: Analysis and Application. Cambridge: Cambridge University Press, 2010.

[29] Bangkokpost. (2012). China Keen To Win Rail Contracts [Online]. Available: http://www.bangkokpost.com/business/economics/325140/china-keen-to-win-rail-contracts [Accessed: 27 September 2013].

[30] M. Hanemann, J. Loomis, and B. Kanninen. (1991). Statistical efficiency of double-bounded dichotomous choice contingent valuation. American Journal of Agricultural Economics [Online]. 73(4), pp. 1255-1263. Available: http://links.jstor.org/sici?sici=0002-9092\%28199111\%2973\%3A4\%3C1255\% 3ASEODDC\% 3E2.0.CO\% 3B2-I [Accessed: 29 December 2012]. 
